LBNL-60449

\title{
Increasing the Fuel Economy and Safety of New Light-Duty Vehicles
}

White paper prepared for the William and Flora Hewlett Foundation's Workshop on Simultaneously Improving Vehicle Safety and Fuel Economy through Improvements in Vehicle

Design and Materials

September 18, 2006

\author{
Tom Wenzel \\ Lawrence Berkeley National Laboratory \\ 1 Cyclotron Road \\ Berkeley, CA 94720 \\ Marc Ross \\ Physics Department \\ University of Michigan \\ Ann Arbor, MI 48109
}

This work was supported by The William and Flora Hewlett Foundation. Prepared for the U.S. Department of Energy under Contract No. DE-AC03-76SF00098. 


\section{DISCLAIMER}

This document was prepared as an account of work sponsored by the United States Government. While this document is believed to contain correct information, neither the United States Government nor any agency thereof, nor The Regents of the University of California, nor any of their employees, makes any warranty, express or implied, or assumes any legal responsibility for the accuracy, completeness, or usefulness of any information, apparatus, product, or process disclosed, or represents that its use would not infringe privately owned rights. Reference herein to any specific commercial product, process, or service by its trade name, trademark, manufacturer, or otherwise, does not necessarily constitute or imply its endorsement, recommendation, or favoring by the United States Government or any agency thereof, or The Regents of the University of California. The views and opinions of authors expressed herein do not necessarily state or reflect those of the United States Government or any agency thereof, or The Regents of the University of California.

Ernest Orlando Lawrence Berkeley National Laboratory is an equal opportunity employer. 


\begin{abstract}
One impediment to increasing the fuel economy standards for light-duty vehicles is the longstanding argument that reducing vehicle mass to improve fuel economy will inherently make vehicles less safe. This technical paper summarizes and examines the research that is cited in support of this argument, and presents more recent research that challenges it. We conclude that the research claiming that lighter vehicles are inherently less safe than heavier vehicles is flawed, and that other aspects of vehicle design are more important to the on-road safety record of vehicles. This paper was prepared for a workshop on experts in vehicle safety and fuel economy, organized by the William and Flora Hewlett Foundation, to discuss technologies and designs that can be taken to simultaneously improve vehicle safety and fuel economy; the workshop was held in Washington DC on October 3, 2006.
\end{abstract}




\section{Table of Contents}

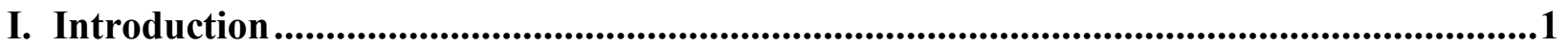

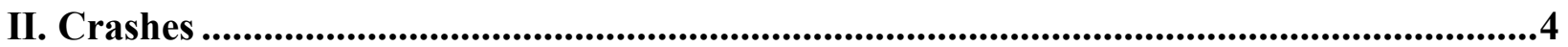

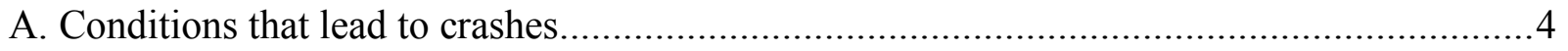

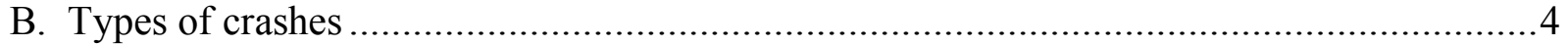

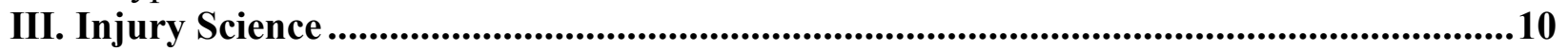

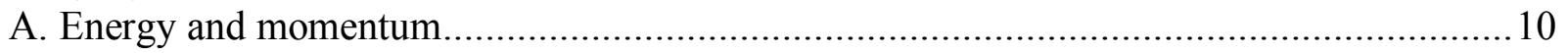

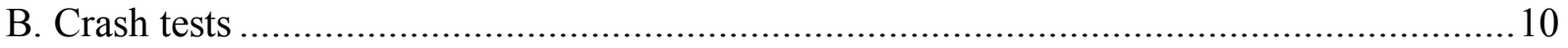

IV. Analyses of on-road fatality rates......................................................................... 12

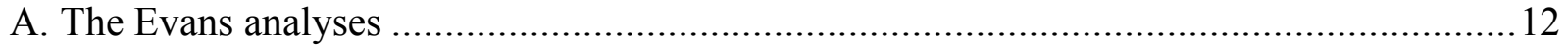

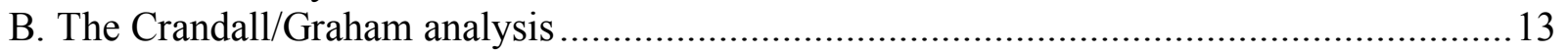

C. The Kahane analyses .................................................................................. 14

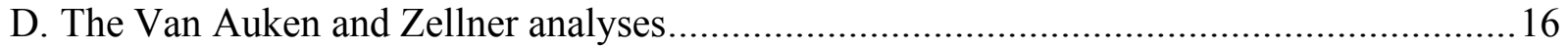

V. On-road risks by vehicle type and model ..................................................................19

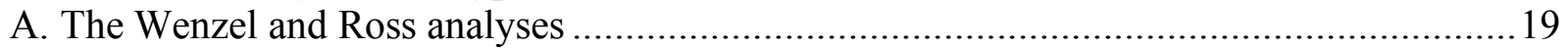

B. The effect of drivers and environment on risk ........................................................2 24

C. Steps to improve the compatibility of cars and light trucks.....................................2

VI. New research on injury causation ...................................................................................28

VII. Conclusions................................................................................................................30

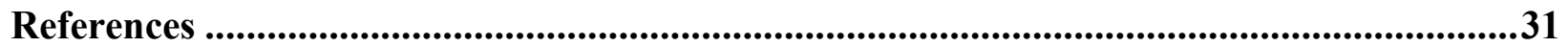




\section{List of Tables}

Table 1. Distribution of 2004 fatal crashes and fatalities (source: FARS)

Table 2. Distribution of 2004 fatal crashes and fatalities, all motorized vehicles (source: FARS) 5

Table 3. Predicted change in 1999 fatalities with a 100-lb reduction in weight of subject vehicle

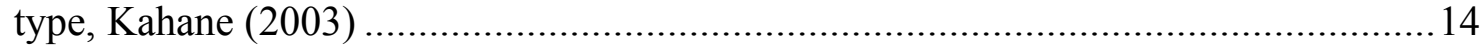

Table 4. Predicted change in 1999 fatalities with a 100-lb reduction in weight of heaviest light trucks (greater than $3,870 \mathrm{lbs}$ ) by crash type, Kahane (2003) ................................ 15

Table 5: Relative driver fatality rate in struck car, by striking vehicle type (Source: Kahane 2003, Table 5, page xix) .............................................................................................. 16

Table 6. Relative driver fatality rate in struck car, by striking vehicle type (Source: Kahane 2003, Table 6-4, page 262).

Table 7. Estimated effect of weight and size reductions on 1999 fatalities, for cars and light trucks (Source: Van Auken and Zellner, 2005b, Tables 2 and 3, page 27, and Tables 5 and 6 , page 36 )

Table 8. Estimated effect of weight and size reductions on 1999 fatalities, for cars and light trucks, by source of effect (Source: Van Auken and Zellner, 2005b, Tables 2 and 3, page 27 , and Tables 5 and 6 , page 36 ). 


\section{List of Figures}

Figure 1. Distribution of new light-duty vehicle sales, by year, type, and EPA weight (curb weight plus 300 lbs; source: Heavenrich 2005) .............................................. 1

Figure 2. Percent of driver fatalities in crashes between two light-duty vehicles, by crash partner

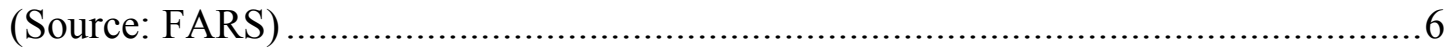

Figure 3. Percent of driver fatalities in crashes between two light-duty vehicles, by crash orientation (Source: FARS) ........................................................................ 7

Figure 4. Percent of driver fatalities in crashes between a car and a light truck, by crash orientation (Source: FARS) ............................................................................. 8

Figure 5. Driver fatality rates in rollover crashes for 1- to 3-year old vehicles, by year and vehicle type

Figure 6. Driver fatality ratio vs. mass ratio for frontal crashes of two cars between 1980 and 2004. Recreated by LBNL using FARS data.

Figure 7. Percent of driver fatalities in car-car frontal crashes, of all fatalities in two-vehicle crashes involving cars and light trucks (Source: FARS)

Figure 8. Risk-to-drivers, and risk-to-drivers-of-other-vehicles, by vehicle type; differences between vehicle types less than $10 \%$ are not statistically significant .....................20

Figure 9. Risk-to-drivers, and risk-to-drivers-of-other-vehicles, by vehicle type; differences between vehicle types less than $10 \%$ are not statistically significant .....................20

Figure 10. Risk-to-drivers in rollover crashes and all other crashes, by vehicle type; differences between vehicle types less than $10 \%$ are not statistically significant ......................21

Figure 11. Risk-to-drivers in rollover crashes and all other crashes, by vehicle type; differences between models less than $20 \%$ are not statistically significant.............................22

Figure 12. Stiff frame rails of pickups and truck-based SUVs (model year 2002 Dodge Ram 150 pickup truck)

Figure 13. SUV risk-to-drivers and risk-to-drivers-of-other-vehicles, by SUV type and model..23

Figure 14. Fuel economy and interior volume of 2005 truck-based and crossover SUV models (4WD versions)

Figure 15. Risk to drivers and to others, by vehicle type and area, California 1995-02 ............25

Figure 16. Effect of bad driver rating and population density on risk-to-drivers, by vehicle type 26

Figure 17. Risk-to-drivers and vehicle weight, for individual car models. 


\section{Introduction}

This technical paper is on the safety impacts of improving the fuel economy of new light-duty vehicles which have been redesigned to meet greenhouse gas reduction and oil savings goals. We do not consider changes in driving practices such as changed speed limits; the reductions are achieved by changing the physical characteristics of the vehicles and the vehicle fleet. (We define fuel economy as miles per gallon using the present laboratory tests.) Our analysis is based on both the traffic risks of past vehicles and those inferred for the new designs. For the new designs, substantial investments in the manufacturing process and a substantial period of time would be involved. But, the long term increase in manufacturing cost per vehicle could be small to moderate.

Vehicle mass is a major factor in fuel economy. In the late 1970s-early 1980s, the most important change in vehicle design was the virtual elimination of the heaviest cars from the new vehicle fleet. Figure 1 shows that the fraction of new vehicles that were over $4000 \mathrm{lbs}$ decreased from $46 \%$ of sales in 1975 ( $40 \%$ cars, $6 \%$ light trucks) to $9 \%$ in 1980 (3\% cars, $6 \%$ light trucks).

Figure 1. Distribution of new light-duty vehicle sales, by year, type, and EPA weight (curb weight plus 300 lbs; source: Heavenrich 2005)

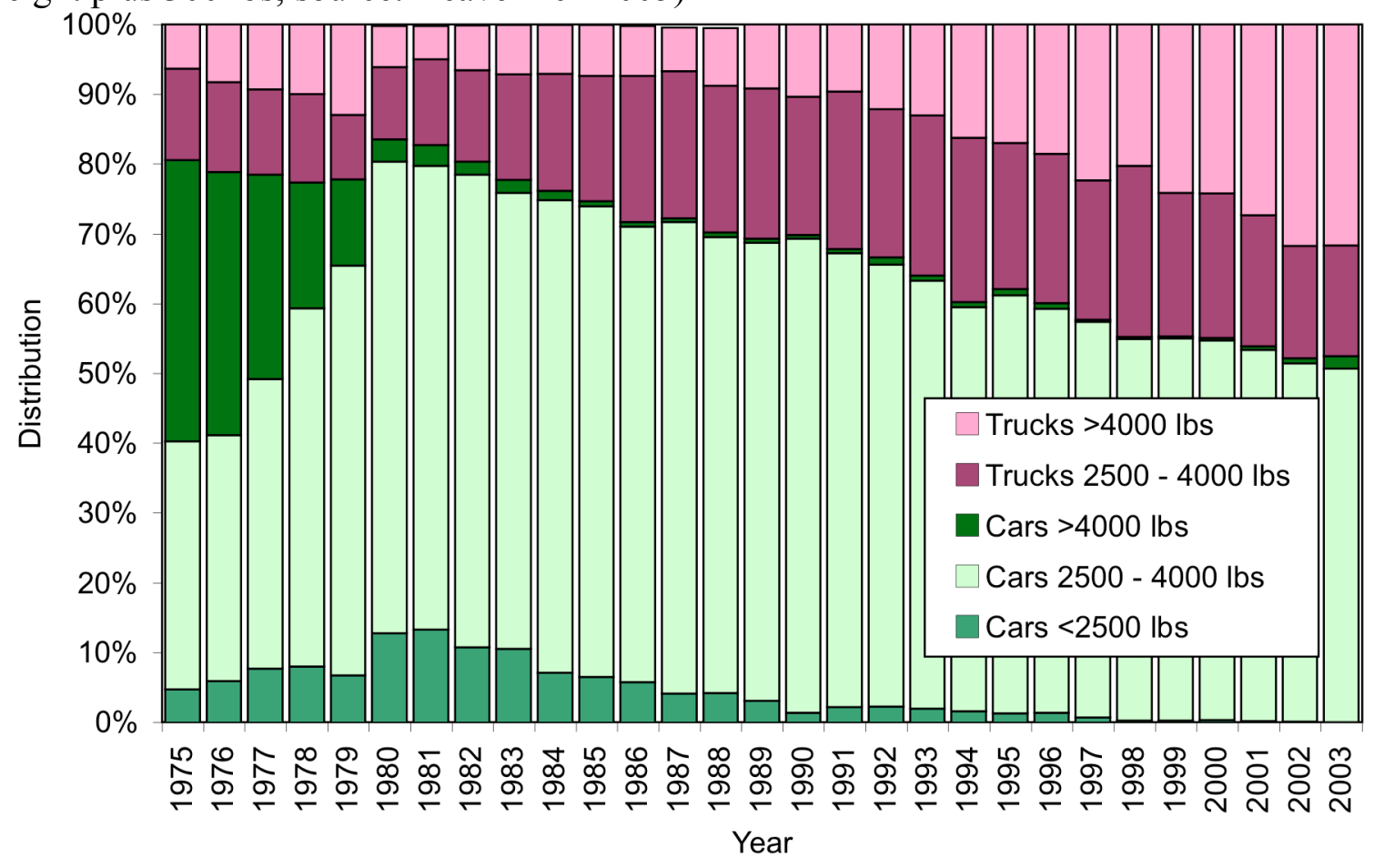

These heavier vehicles remained a small part of the new vehicle fleet until the late 1980's, when the sales of heavier light trucks, many used as substitutes for cars, began to increase. By 2003 the fraction of light trucks over $4000 \mathrm{lbs}(32 \%)$ was approaching the level of heavy car sales in $1975(40 \%)$.

If the mass of a typical modern car were reduced 10\%, the fuel economy would be increased $3 \%$ to $8 \%$ (An et al., 2002). The low benefit would roughly characterize mass reduction without a 
compensating reduction in engine displacement. The high benefit would characterize a vehicle with the same "performance", i.e. with a smaller engine to match the reduced weight (albeit with higher engine speeds to maintain the same drivability).

There are several ways to reduce a vehicle's mass: a) Design optimal components and local structures to reduce mass. For a given vehicle class/size (e.g. midsize car), as surveyed in the early 1990s, there was a large variation in the masses of production vehicles (DeCicco and Ross, 1993). Much of that opportunity still remains. b) Change the basic vehicle structure of conventional body-on-frame SUVs and pickups, by using a car-based unibody design, as in the so-called crossover SUVs (presented and discussed in connection with figures 13 and 14 below), and in the Honda Ridgeline pickup truck. c) Adopt lighter propulsion components, especially small engines capable of switching to high power by operating at high-speed or with turbocharge (Shahed, 2006). In addition, simpler and lighter transmissions can be used, like automatic "manual" or double clutch. d) Continue to increase the content of light materials, such as highstrength steels supported by advanced steel forming (DeCicco, 2005), light metals (aluminum and magnesium), and fiber-reinforced plastics (Lovins et al., 2005). Finally, smaller vehicles can be built. Because typical designs are not optimal, relatively safe small vehicles can be built primarily for use on urban roads.

Mass has just one intrinsic property critical to safety that is independent of design and materials: in a collision with another vehicle or a roadside object, the lighter of the pair is more strongly decelerated. Depending on the details of the crash, the stronger deceleration may create a greater risk to an occupant of a light vehicle. But this additional risk is relatively small compared to what frequently happens in a serious crash: a) intrusion of another vehicle or roadside object into the passenger compartment of the vehicle in question, b) rollover of the vehicle, or c) failure of the restraints to keep the occupants away from contact with hard interior surfaces.

The key issue to prevent intrusion is the strength of the passenger compartment and the height and stiffness of the collision partner. It is practical to use stronger materials and more compatible designs to reduce casualties in two-vehicle collisions; some crossover SUVs are designed with this in mind. Mass is not intrinsic to any of this; for example, light honeycomb or fiber-reinforced materials sever the historical connection between mass and strength.

The key issue to prevent rollover is to lower a vehicle's center of gravity. Although SUVs and pickups are more likely to roll over than passenger cars, the height of a vehicle's center of gravity, and not mass, determine the propensity of a vehicle to roll over. The propensity to rollover can be reduced by lowering the center of gravity and/or by increasing the trackwidth. Electronic stability control (ESC) is a new technology that provides automatic braking to inhibit rollovers from occurring. Once a rollover occurs, the crush resistance and performance of the roof will affect whether a belted occupant will be injured, and whether the occupants are belted will affect whether they are ejected (ejection is likely to result in serious to fatal injury).

Restraints (both safety belts and air bags) and interior padding provide important protection to occupants in all types of crashes. Side curtain air bags, which reduce head contacts with windows, are becoming more prevalent, and an increasing number of these systems can be triggered in a rollover. Advanced seat belts, with pretensioners and load limiters, are being 
incorporated in many models. Under research are four-point seatbelts, which would hold occupants in position in side-impact crashes better than today's three-point lap/shoulder belts. Improved restraints would also better control the deceleration in crashes with roadside objects, and thus further minimize the historical relationship between vehicle mass and safety.

Although vehicle mass is not intrinsic to improving occupant safety, currently safety technologies, such as ESC, curtain side airbags, and advanced seat belts, tend to be included in heavier, and more expensive, car models.

The purpose of this paper is to demonstrate that there is little, if any, trade-off between improvements in fuel economy and in safety in light motor vehicles, particularly if priority is given to both of these goals. A reduction in vehicle mass is an important technique for improving fuel economy, but certainly not the only or even the most effective one. While lighter vehicles are at a disadvantage in crashes with heavier ones, this does not suggest that a general reduction in vehicle weight across all vehicle types would have a significant impact on safety nor even on vehicle size. This is not only because the physics of the situation concerns only the relative masses of colliding vehicles, but because a substantial majority of casualties in motor vehicle crashes are unrelated to the masses of the vehicles involved. 


\section{Crashes}

\section{A. Conditions that lead to crashes}

Crashes that result in serious injuries and deaths are associated with dangerous vehicles, hazardous roads, and driving errors. Driver mistakes have many causes, including drowsiness, inexperience, aggressiveness, alcohol, and distractions. "Microsleep" events at the wheel may be the cause of $25 \%$ of serious crashes (Horne and Raynor, 1995; NHTSA, 2006, chapter 7). Teenage male drivers are involved in roughly 4 times more fatal crashes per mile than over-25 year olds. (Massie et al., 1995; Kahane, 1997, page 6) Use of cellular telephones has been strongly implicated with increased crash rates (McEvoy et al., 2005; McCartt et al., 2005).

Rural roads (other than interstates) are often poorly designed. They are often narrow; shoulders may be poor or missing; the roads are unlighted and poorly signed. On some roads, traffic greatly exceeds design speeds and carrying capacity, as rural areas have become increasingly suburban. Also, budgets for enforcement are often too limited, and EMS is remote. Half of traffic fatalities in the US occur in counties with less than 70 households per square mile. Less than $30 \%$ of the US population lives in these counties, but they cover $90 \%$ of the land area. The cost of improving many of those roads would be high. Of course, drivers share the responsibility for those deaths. Many roads simply require special driver care to be negotiated safely. We believe that, if economically justified, roads should be improved so that an unusual level of driver attention is not required. However, unsafe driving and unsafe roads cannot be eliminated.

As with roads, a driver needs to be aware of his vehicle. He or she is responsible; if she is tired, she should find a chance to rest; if inexperienced, he should drive less aggressively; and if the vehicle has limitations like less than excellent handling and brakes, the driver should drive more defensively. Many analysts believe that essentially all responsibility for crashes rests with drivers. They let the vehicle manufacturers off the hook. We believe that if there are safety technologies and vehicle designs that would reduce risk at an acceptable cost it is the responsibility of regulators and manufacturers to see them incorporated in new vehicles.

\section{B. Types of crashes}

Vehicle crashes and casualties come in many categories and their analysis is complicated. However, one can simplify by focusing on the most important categories. The simplified picture is still very rich, and not misleading about the whole. First, as shown in Table 1, 82\% of all vehicles involved in fatal crashes are light-duty vehicles, and account for $85 \%$ of fatalities. Motorcycles account for another $8 \%$ of vehicles in fatal crashes, and $12 \%$ of fatalities. 
Table 1. Distribution of 2004 fatal crashes and fatalities (source: FARS)

\begin{tabular}{|l|cc|cc|}
\hline \multirow{2}{*}{ Vehicle type } & \multicolumn{2}{|c|}{ Vehicles } & \multicolumn{2}{c|}{ Occupant deaths } \\
Cars & Number & Percent & Number & Percent \\
\hline SUVs & 25,512 & $44 \%$ & 19,092 & $51 \%$ \\
Vans (including minivans) & 7,781 & $13 \%$ & 4,735 & $13 \%$ \\
Pickups & 3,671 & $6 \%$ & 2,036 & $5 \%$ \\
Other light trucks & 10,773 & $18 \%$ & 5,801 & $16 \%$ \\
\hline Subtotal, light-duty vehicles & 127 & $0 \%$ & 35 & $0 \%$ \\
Buses and medium-/heavy-duty trucks & 47,864 & $82 \%$ & 31,699 & $85 \%$ \\
Motorcycles & 5,195 & $9 \%$ & 832 & $2 \%$ \\
Other & 4,446 & $8 \%$ & 4,344 & $12 \%$ \\
Unknown & 211 & $0 \%$ & 143 & $0 \%$ \\
\hline Total & 698 & $1 \%$ & 124 & $0 \%$ \\
\hline
\end{tabular}

As indicated in Table 2, only $40 \%$ of fatal crashes are multi-vehicle events, accounting for only $42 \%$ of fatalities; these crashes are almost always within the driving lanes. $46 \%$ of fatal crashes, and $45 \%$ of fatalities, are single-vehicle events, with the vehicle either crashing into an object such as a tree or pole, or rolling over; $26 \%$ of all traffic fatalities (and 30\% of all vehicle occupant fatalities) in 2004 came from vehicle rollovers, either as a first or subsequent event. In $95 \%$ of single-vehicle crashes, the crash occurs outside the driving lanes (FARS). Most of the remaining $13 \%$ of crashes and fatalities involve crashes with pedestrians or bicyclists.

Table 2. Distribution of 2004 fatal crashes and fatalities, all motorized vehicles (source: FARS)

\begin{tabular}{|l|cc|cc|cc|}
\hline & \multicolumn{2}{|c|}{ Crashes } & \multicolumn{2}{c|}{ Fatalities } & \multicolumn{2}{c|}{ Occupant Fatalities } \\
Crash type & Number & Percent & Number & Percent & Number & Percent \\
\hline $\begin{array}{l}\text { Two- (or multi-) vehicle } \\
\text { crashes }\end{array}$ & & & & & & \\
One-vehicle crashes into & 15,451 & $40 \%$ & 17,937 & $42 \%$ & 17,937 & $48 \%$ \\
object such as tree & 13,177 & $34 \%$ & 14,068 & $33 \%$ & 14,068 & $38 \%$ \\
$\begin{array}{l}\text { Non-collisions } \\
\quad \text { First event rollovers }\end{array}$ & 4,554 & $12 \%$ & 4,964 & $12 \%$ & 4,964 & $13 \%$ \\
Vehicle crashes with & & & 3,828 & $9 \%$ & 3,828 & $10 \%$ \\
pedestrians or bicyclists & 5,028 & $13 \%$ & 5,604 & $13 \%$ & 28 & $0 \%$ \\
Other & 43 & $0 \%$ & 39 & $0 \%$ & 39 & $0 \%$ \\
\hline Total & 38,253 & $100 \%$ & 42,612 & $100 \%$ & 37,036 & $100 \%$ \\
\hline
\end{tabular}

Note: $72 \%$ of vehicles in non-collisions are classified as first-event rollovers in FARS, while $35 \%$ of vehicles in one-vehicle crashes are considered subsequent-event rollovers; the incidence of rollovers in other types of crashes is negligible. $19 \%$ of vehicles, $26 \%$ of all fatalities, and $30 \%$ of all occupant fatalities are associated with a first or subsequent rollover, regardless of the crash type. FARS is NHTSA's Fatality Analysis Reporting System, a census of all traffic fatalities on public roadways in the U.S.

Fatal crashes between cars and light-duty trucks, and between two light-duty trucks, have been increasing, while crashes between two cars have been decreasing (Figure 2). These trends are due to a combination of the increased popularity of light trucks, including minivans, SUVs, and pickups, as well as a reduction in car-car crash fatalities due to improvements in car designs and increased use of (improved) seat belts and airbags. The result is an increase in the fraction of 
Figure 2. Percent of driver fatalities in crashes between two light-duty vehicles, by crash partner (Source: FARS)

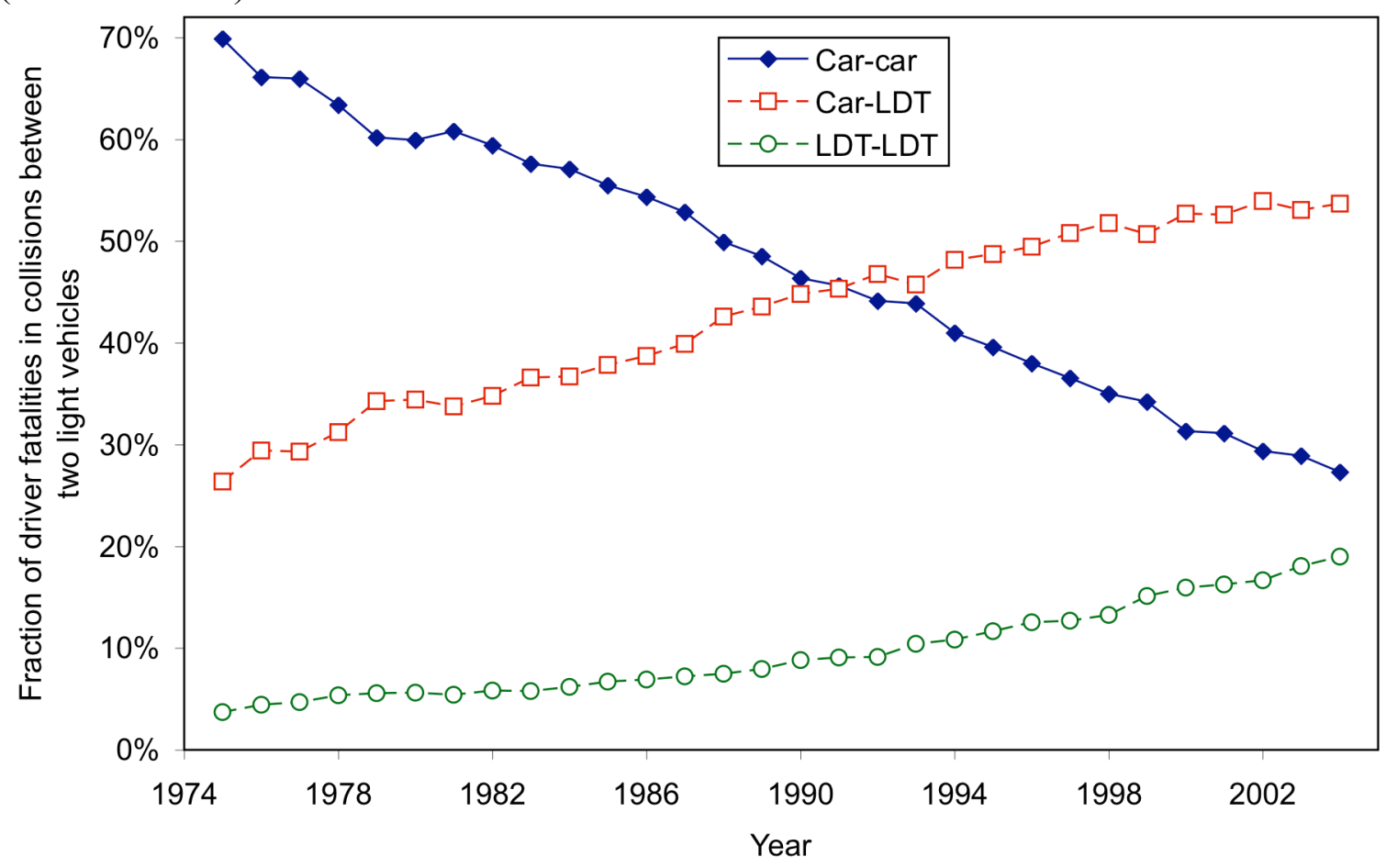

fatalities in crashes between cars and light trucks, from $26 \%$ to $54 \%$ (Figure 2), as well as an increase in the fraction of driver fatalities in angle crashes, from $36 \%$ to $49 \%$ (Figure 3). In particular, fatalities in "angle" crashes in which one vehicle strikes the other in the side have been increasing rapidly, from $10 \%$ in 1975 to $28 \%$ in 2004 (Figure 4; the angle crashes shown include both trucks striking cars in the side and vice versa). 
Figure 3. Percent of driver fatalities in crashes between two light-duty vehicles, by crash orientation (Source: FARS)

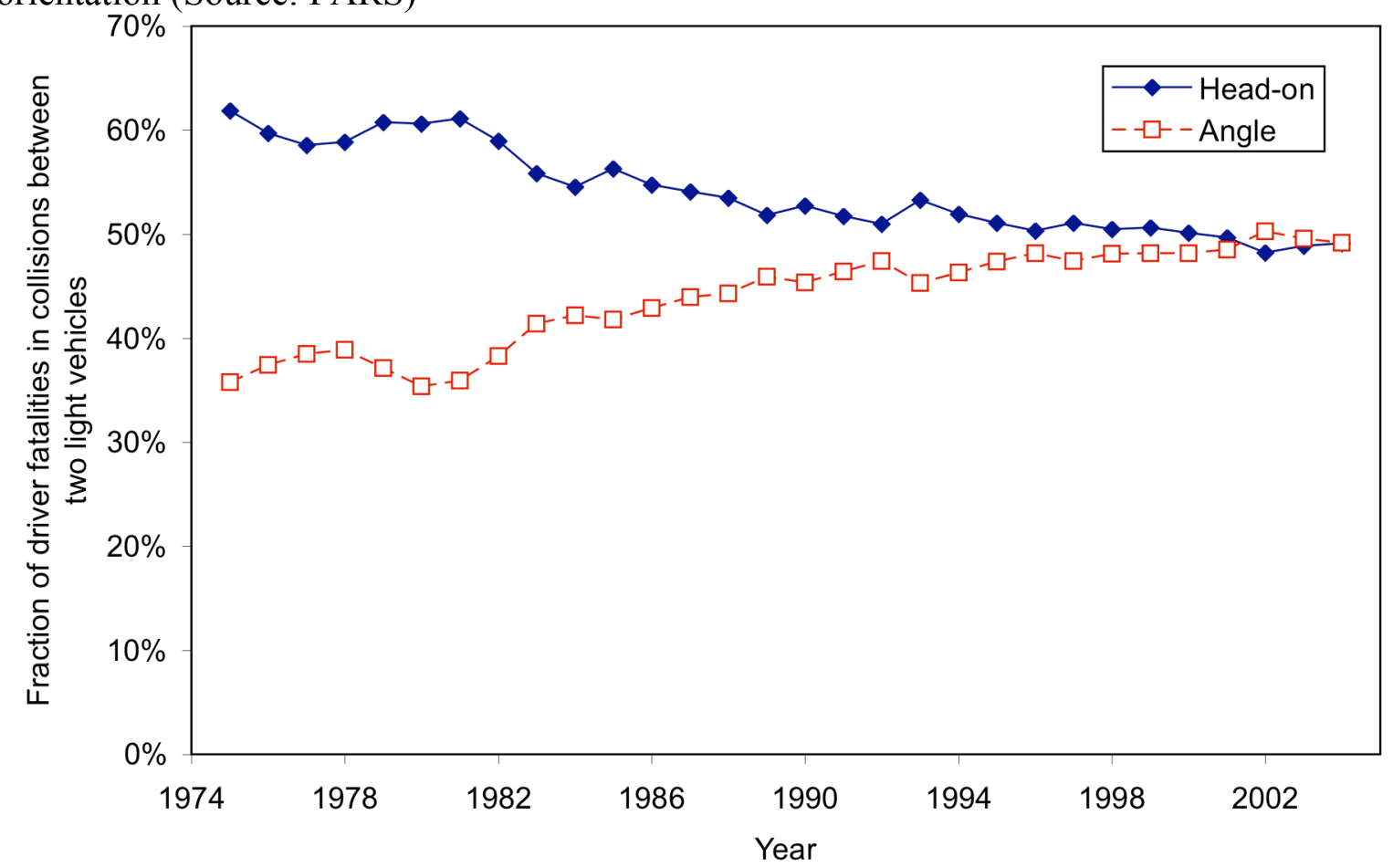

Figure 5 shows how vehicle design has affected the fatality rate in new vehicles over time. The fatality rate is the number of fatalities divided by the number of vehicles sold, and is calculated for certain types of crashes in Figure 5 by vehicle type. Fatality rates are more instructive than the number of fatalities because of the dramatic increase in the number of light trucks, particularly SUVs, in use. Although one-quarter of all traffic fatalties in 2004 came from vehicle rollovers, and the total number has not changed much in twenty years, Figure 5 shows that the fatality rate in new SUVs has been cut in half over the last six years (from 46 to 19 fatalities per million vehicles). This decline can be attributed to manufacturers reducing the center of gravity and increasing the track width in newer SUV models, particularly the car-based "crossover" SUVs, making them more stable and less likely to rollover. The rollover fatality rate in new cars has shown a consistent and steady decrease between 1977 and 2005 (from 35 to 19 fatalities per million vehicles). 
Figure 4. Percent of driver fatalities in crashes between a car and a light truck, by crash orientation (Source: FARS)

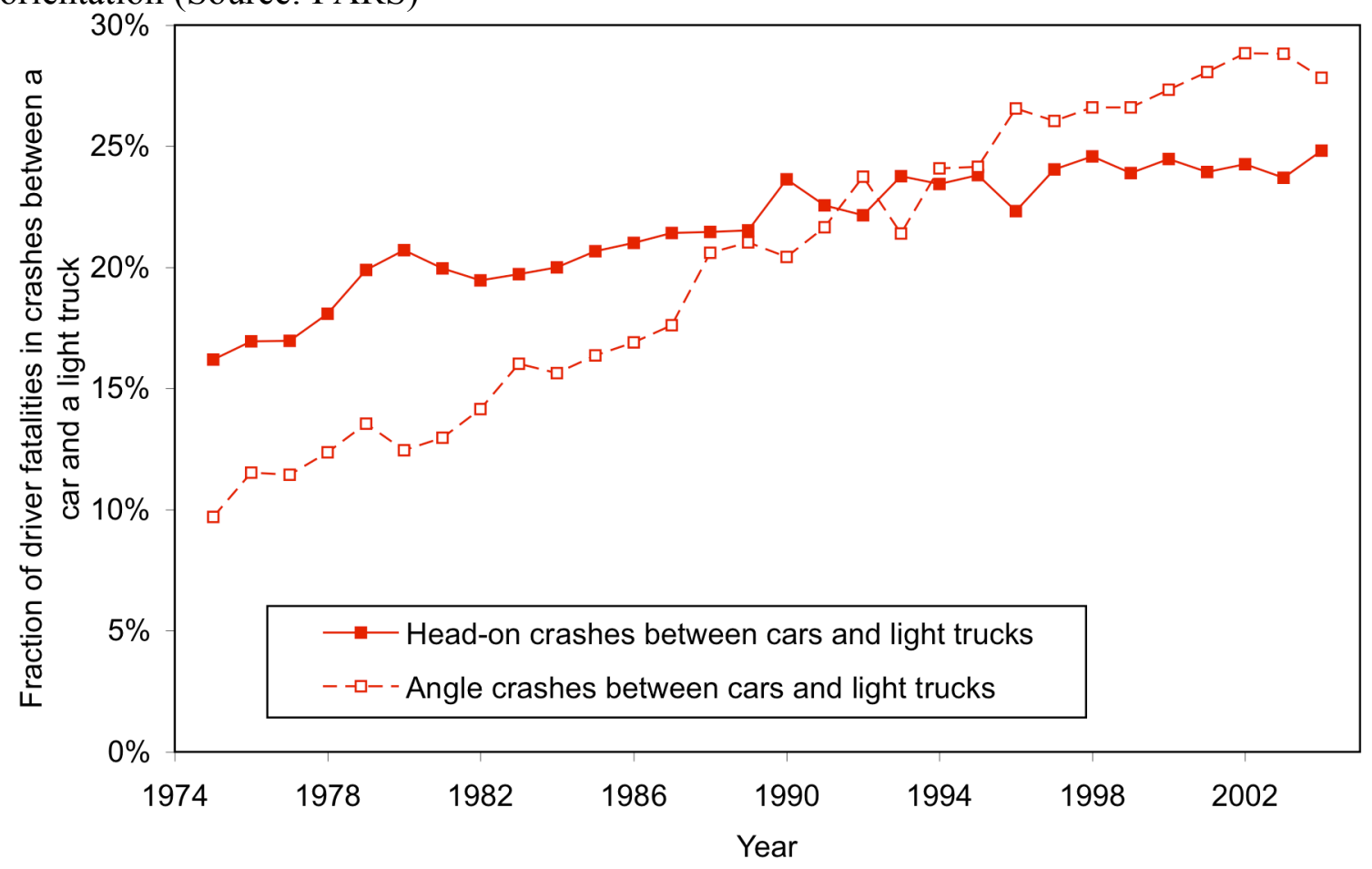

Figure 5. Driver fatality rates in rollover crashes for 1- to 3-year old vehicles, by year and vehicle type

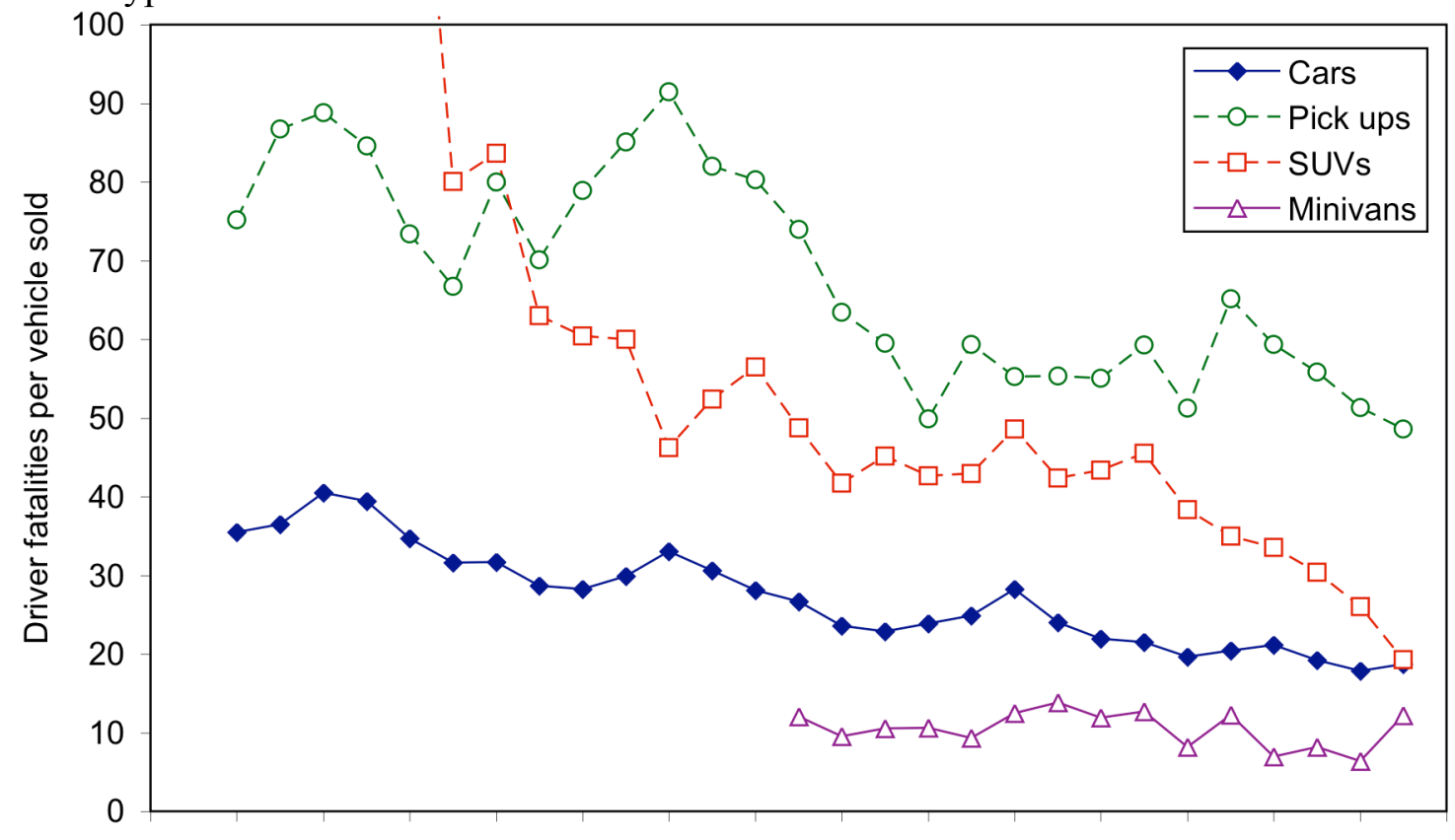

1976197819801982198419861988199019921994199619982000200220042006

Year 
Deaths in rollovers and in other single-vehicle crashes should continue to decrease in the near future as a result of on-board "active safety" equipment in many new vehicles. The main innovation is stability controls, in which brakes are applied automatically and independently at the four wheels in a way that inhibits uncontrolled vehicle skidding and rollover. In addition, rollover fatalities can be further reduced by strengthening vehicle roofs and pillars.

In this paper we focus on vehicle occupants, neglecting pedestrian and bicyclist deaths. Thus, we focus on the first three rows of Table 2 , the $87 \%$ of traffic deaths that involve occupants in twovehicle (mostly front-to-front and front-to-side) crashes, single-vehicle crashes into objects, and non-collision (mostly rollover) crashes. 


\section{Injury Science}

\section{A. Energy and momentum}

Traditionally, a motor-vehicle crash is described as a sequence of three "collisions". In the first, the vehicle strikes another vehicle or, an object, or rolls over, or a combination of these. The vehicle's exterior is partially crushed. As some of the energy of motion is transformed into crush energy, the remaining relative motion may be shared among the interacting bodies, which can be good because it may reduce speeds. Depending on the crash severity, the location and direction of crash force, and the stiffness of the vehicle and of the colliding object, the crush can intrude into the vehicle's passenger compartment, which is potentially very dangerous.

In the second "collision", occupants strike interior surfaces of the vehicle and restraints. Restraints, seat belts, air bags, and perhaps padding, have reduced injuries from this type of collision. In future vehicles, occupants would primarily interact with restraints, or with intrusions, if the crash is of high-severity or unfavorable geometry.

The third "collision", involves crashes among parts of each occupant's body, such as organs and skeleton. If the contact between an occupant and a hard surface is brief enough, the interaction among parts of the body will be small and the occupant may avoid injury.

A vehicle which tends to absorb a lot of the crash energy, crushing structures in the space between its exterior and the passenger compartment, can protect occupants from forceful contact. This is particularly promising in front; however, there is little space in which to absorb energy and protect the near occupant in a crash at the side. According to the momentum principle, lowmass vehicles may rebound strongly from crashes. Vehicles with low mass have been criticized for putting their occupants at risk in this connection. But is such a recoil-related injury probable? We will discuss the issue in Section VI.

\section{B. Crash tests}

Historically vehicles have not been instrumented to record crash information (although some vehicles now come with event data recorders). Although there are hundreds of pieces of information that are systematically collected about each fatal crash in the US, and reported in FARS, the most critical physical parameters, like vehicle speeds, timing, and forces, are not known. (The velocities may be known if the vehicle had an event data recorder, but that information is not part of the public database. Moreover, "delta-V", a second velocity-related characteristic based on the crush energy of a vehicle in a crash, is only determined in a small sample of cases using expert measurements and computation.) Thus, rather than depending on actual on-road experience, the crashworthiness of vehicles tends to be evaluated using standardized laboratory crash tests. The primary tools are a frontal test and a side test, in which each vehicle is instrumented and carries an instrumented dummy, and a rollover test. In the frontal and side tests, the vehicle is crashed in a prescribed manner against a "barrier". The barrier may artificially represent another vehicle, or it may be a pole which is a frequent onevehicle crash hazard. These tests are highly valuable to vehicle designers. 
It is useful to distinguish between the two general characteristics of vehicles that protect their occupants from death or serious injury in a crash: crash avoidance and crashworthiness. Crash avoidance is the ability of a vehicle, through driver-controlled and automatic handling and braking, to avoid a serious crash altogether. Although braking distances of vehicles are regulated and tested, other means of crash avoidance are not. Consumers Union conducts handling and braking tests on vehicles. Crashworthiness refers to the ability of a vehicle to protect its occupants once a crash has occurred. Under the New Car Assessment Program (NCAP), the National Highway Traffic Safety Administration (NHTSA) conducts crash tests in a laboratory setting to ensure that new vehicles comply with crashworthiness standards. A 5-star ranking based on the results of NCAP testing is assigned to each vehicle model, and made publicly available on the NHTSA website. Currently NHTSA conducts tests of frontal, side impact, and rollover crashes for the NCAP program. The Insurance Institute of Highway Safety (IIHS) conducts these and other tests, and publicizes their results on their website. Vehicle manufacturers have striven to improve the designs of their vehicles to ensure that they do not receive a low NCAP score. When they were first introduced in 1979, no vehicles received 5 stars on the frontal test, and many earned only 1 or 2 stars. Virtually all of the newest model year cars now earn 4 or 5 stars, at least on the frontal impact test (GAO, 2005). For example, the Elantra recently improved from 3 to 5 stars, an improvement supported by a $30 \%$ reduction in on-road risk. The Focus similarly improved from the model it replaced, the Escort.

This history strongly suggests that regularly conducted standardized tests are needed for the compatibility of cars being struck on the side by popular body-on-frame light trucks. Standardized tests have proven to be powerful motivators of safety redesigns and innovation.

There is another issue: As important as crash tests have been, they do not adequately measure vehicle safety for purposes of consumer information (although it is often implied that they do). The risks in actual driving only weakly correlate with crash test results (Newstead et al., 2002). The weakness of the correlation is not adequately explained by the uncertainty associated with driver behavior. A major reason is that the crash speed of the side impact test is not high enough to yield less than top ranking for most vehicles (Arbelaez et al., 2005). And the test barrier is too low to mimic car crashes with the high bumpers and fronts of many light trucks. Yet there are more than enough such crash deaths on the road to justify a change in the test.

As useful as crash tests have been, they have not been effective in settling our issue, mass and safety. 


\section{Analyses of on-road fatality rates}

\section{A. The Evans analyses}

Perhaps the earliest statistical analysis of on-road vehicle crashworthiness was conducted by Leonard Evans (Evans, 2004a; Evans, 2004b). Evans studied the ratio of fatality rates of the drivers of two cars in head-on collisions. Evans took the ratio of the number of driver fatalities in the lighter car to the number of driver fatalities in the heavier car, and plotted those ratios against the ratio of the weights of the two cars. Evans found that the fatality ratio between drivers of two cars increased strongly as the mass ratio between the cars increased; for example, in Figure 6, if the mass of two cars differs by a factor of two, the fatality risk to the driver in the lighter car is 12 times $\left(2^{3.56}=12\right)$ that of the driver in the heavier car.

Figure 6. Driver fatality ratio vs. mass ratio for frontal crashes of two cars between 1980 and 2004. Recreated by LBNL using FARS data.

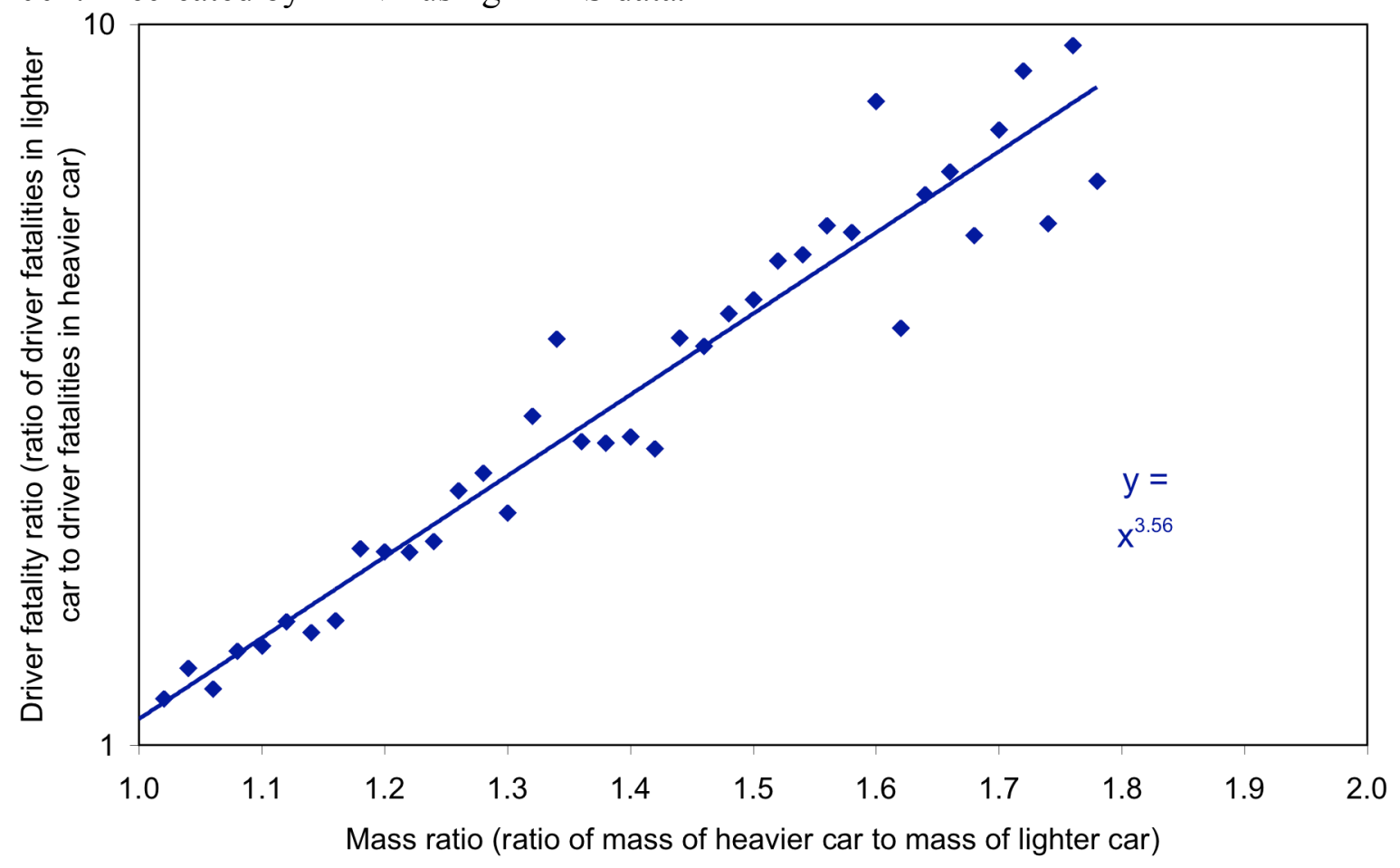

Evans' striking graph based on fatality ratios was extremely influential in supporting the argument that mass, or more precisely, the mass ratio between vehicles, is the primary vehicle attribute that protects occupants, and that reductions in mass will inherently lead to increases in fatalities. He supported this interpretation arguing that the principle of momentum explains why heavy cars protect their occupants better than light cars. However, if correct, Evans' results suggest that fatalities will increase only if the disparity in mass between vehicles increases; if all vehicles are made lighter, or the mass disparity reduced, his results suggest that fatalities will decrease.

Although Evans' plot looks impressive, there are critical flaws. First, Evans analysis, by its definition, doesn't distinguish aggressiveness, vehicle designs that tend to kill people in other 
vehicles in frontal collisions, from protectiveness, vehicles that protect their own occupants. Using Evans' ratio, a car design that tends to kill others appears as a safety attribute! Second, one may not be learning about implications of mass, but about design characteristics that have correlated with mass in past designs; and they may correlate less strongly in designs of the future. Finally, the contribution of frontal crashes between two cars to the total number of driver fatalities in crashes between two light-duty vehicles has declined substantially, from $36 \%$ of all driver fatalities in 1980 to $14 \%$ in 2004 (Figure 7). As discussed above, this decline is a result of: (1) improved crashworthiness of cars, due in part to frontal crash testing and improved seat belt design and use, and inclusion of airbags; and (2) increasing numbers of pickups, SUVs, and minivans on the road. As a result, frontal crashes between two cars account for a smaller fraction of fatalities now than other crash/vehicle combinations.

Figure 7. Percent of driver fatalities in car-car frontal crashes, of all fatalities in two-vehicle crashes involving cars and light trucks (Source: FARS)

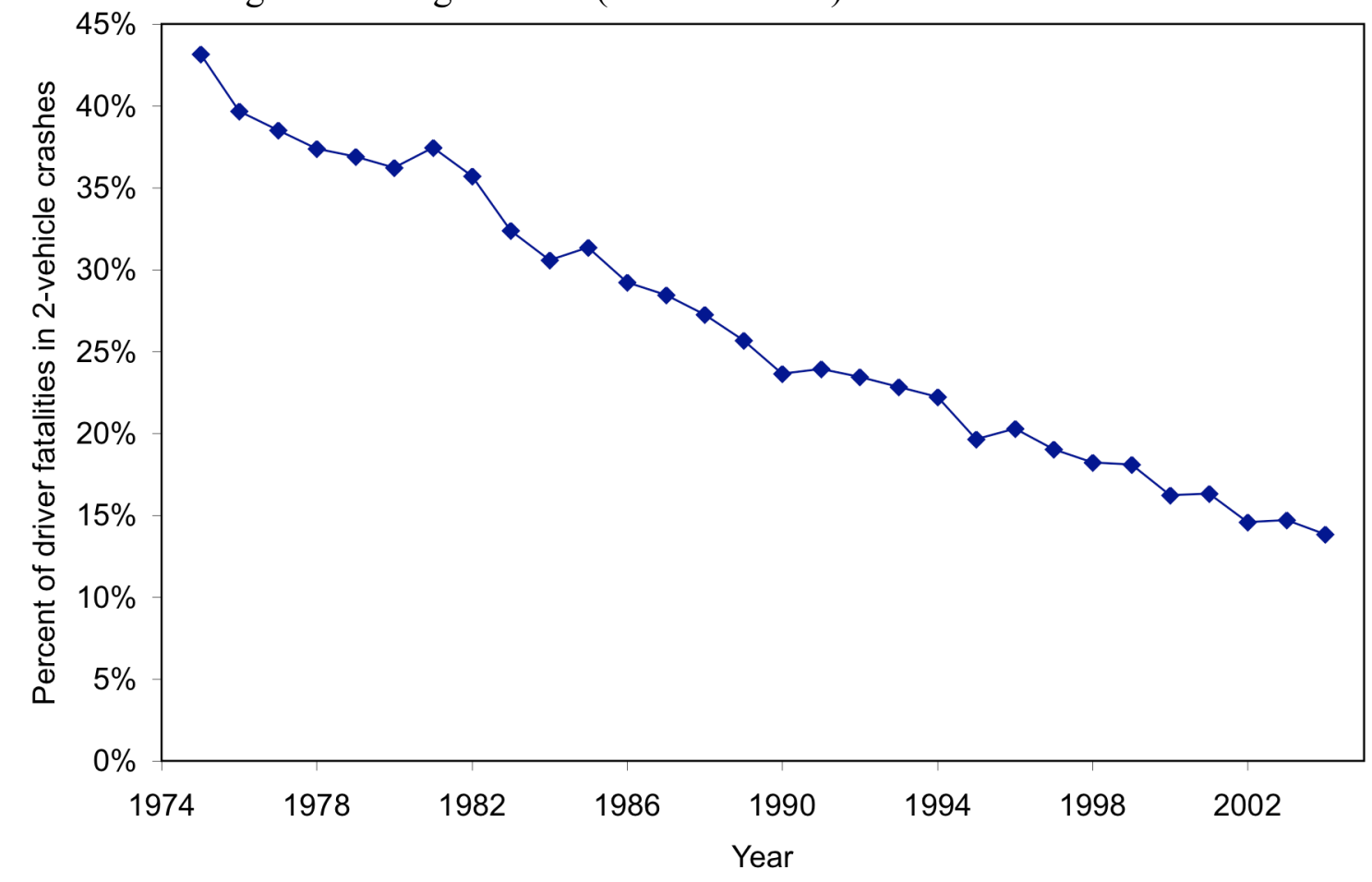

B. The Crandall/Graham analysis

Crandall and Graham (1989) created a regression model to predict national traffic fatalities based on predicted average vehicle weight, using annual national data from 1947 to 1981 . They found that the increase in average weight over time coincided with a decrease in fatalities, and concluded that CAFÉ fuel economy standards enacted in 1978 lowered average vehicle weight, and resulted in a $14 \%$ to $28 \%$ increase in fatalities. However, the analysis included only the first four years that CAFÉ standards were in effect; since that time average fuel economy of new vehicles has changed little, but average weight has increased. Khazoom (1994) provided a critique of Crandall and Graham, and developed an alternative model using state-level data on single-vehicle car crashes between 1985 and 1989. He found that increased car weight increased the number of fatalities, at least in single-vehicle car crashes. 
Although they do not directly assess the relationship between vehicle weight and safety, two recent analyses refute Crandall and Graham's contention that CAFÉ standards increased fatalities. Noland (2004) used state level data from 1975 to 1998, and found a statistical increase in fatalities with increasing fuel economy of new vehicles only if years 1975 to 1977 were included in the model; if those years were excluded there was no statistically significant relationship between fuel economy and fatalities. And Ahmad and Greene (2004) updated the Crandall and Graham analysis using national data from 1966 to 2002, finding that an increase in average new vehicle fuel economy resulted in a statistically significant decrease in traffic fatalities. However, neither of these two studies controlled for vehicle weight or size, both of which have been increasing since 1981 as the number of fatalities per vehicle have been decreasing.

\section{The Kahane analyses}

The next influential analyses on vehicle mass and safety were conducted by the NHTSA statistician, Charles Kahane, in two separate studies (Kahane 1997, Kahane 2003, Kahane 2004). Kahane combined fatality data in FARS with vehicle exposure data from police-reported crash databases to construct regression models that predict the change in driver fatalities in different crash types from reductions in the average mass of vehicles. The Kahane analysis was an improvement over Evans in that it accounted for crash avoidance as well as crash-worthiness, and examined the effects of weight reductions on fatalities in all types of crashes. Kahane went to great lengths to account for driver characteristics, to the extent they were available, in his regression models. Table 3 summarizes the results of his most recent analysis.

Table 3. Predicted change in 1999 fatalities with a 100-lb reduction in weight of subject vehicle type, Kahane (2003)

\begin{tabular}{|l|c|c|c|c|}
\hline $\begin{array}{l}\text { Vehicle } \\
\text { type/weight } \\
\text { reduction } \\
\text { scenario }\end{array}$ & $\begin{array}{c}\text { Actual } \\
\text { fatalities in } \\
1999 \text { crashes }\end{array}$ & $\begin{array}{c}\text { Effect of 100-lb weight } \\
\text { reduction (holding } \\
\text { weight of other vehicles } \\
\text { constant) }\end{array}$ & $\begin{array}{c}\text { Predicted net } \\
\text { change in 1999 } \\
\text { fatalities }\end{array}$ & $\begin{array}{c}\text { Uncertainty } \\
\text { range of } \\
\text { prediction* }\end{array}$ \\
\hline Cars $<2,950 \mathrm{lbs}$ & 13,608 & $+4.39 \%$ & +597 & +226 to +715 \\
Cars $>2,950 \mathrm{lbs}$ & 10,884 & $+1.98 \%$ & +216 & +129 to +303 \\
\hline LDTs $<3,870 \mathrm{lbs}$ & 8,057 & $+2.90 \%$ & +234 & +59 to +296 \\
LDTs $>3,870 \mathrm{lbs}$ & 14,705 & $+0.48 \%$ & +71 & -156 to +241 \\
\hline
\end{tabular}

* $95 \%$ confidence interval

Table 3 indicates that a 100-lb reduction in the average vehicle weight of a particular group, while holding constant the weights of the other three groups, would result in a net increase in overall fatalities. For example, a 100-lb reduction in the average weight of the lightest cars (under 2,950 lbs), holding the weights of all other vehicles constant, would result in a net 597 increase in fatalities. This finding holds true for all crash types, for cars and the lightest light trucks. While the increase in risk associated with reduction of the weight of the heaviest trucks is not statistically solid, Kahane's results consistently show that weight reduction increases risk. 
However, reducing the weight of the heaviest (greater than 3,870 lbs) light trucks is predicted to reduce fatalities in certain types of crashes, as shown in Table 4. A 100-lb reduction in the average weight of the heaviest light trucks would reduce fatalities in crashes between the heaviest light trucks and cars, and crashes between the heaviest light trucks and other light trucks. However, under this scenario fatalities would increase in rollovers and one-vehicle crashes involving the heaviest light trucks, as well as crashes between the these light trucks and pedestrians and heavy trucks. The net result from weight reduction in the heaviest light trucks is a small, but not statistically significant, increase (71) in overall fatalities. The importance of Table 4 is that the effect of the 100-lb mass reduction varies widely with crash type, increasing fatalities in some types of crashes and reducing them in others. Let us pursue this issue further.

Table 4. Predicted change in 1999 fatalities with a 100-lb reduction in weight of heaviest light trucks (greater than $3,870 \mathrm{lbs}$ ) by crash type, Kahane (2003)

\begin{tabular}{|c|c|c|c|}
\hline Crash type & $\begin{array}{c}\text { Actual } \\
\text { fatalities in } \\
1999 \text { crashes }\end{array}$ & $\begin{array}{l}\text { Effect of 100-lb } \\
\text { weight reduction } \\
\text { (holding weight of } \\
\text { other vehicles } \\
\text { constant) }\end{array}$ & $\begin{array}{l}\text { Predicted net } \\
\text { change in } \\
1999 \text { fatalities }\end{array}$ \\
\hline Principal rollover & 2,183 & $+2.56 \%$ & +56 \\
\hline Hit object & 2,639 & $+3.06 \%$ & +81 \\
\hline Hit pedestrian/bicycle/motorcycle & 2,043 & $+0.13 \%$ & +3 \\
\hline Hit heavy truck ( $>10,000$ GVWR) & 860 & $+0.62 \%$ & +5 \\
\hline Hit passenger car & 5,186 & $-0.68 \%$ & -35 \\
\hline Hit another light truck $(<3,870 \mathrm{lbs})$ & 1,010 & $-1.50 \%$ & -15 \\
\hline Hit another light truck $(>3,870 \mathrm{lbs})$ & 784 & $-3.00 \%$ & -24 \\
\hline Overall & 14,705 & $+0.48 \%$ & +71 \\
\hline
\end{tabular}

The critically important limitation of the Kahane analyses is that he used weight as the sole vehicle characteristic in his regression models. His motivation may have been: the historical importance given to weight in other vehicle safety analyses (aka Evans); the purported historical correlation between weight and size; and the relative ease of obtaining information on weight (particularly for cars). ${ }^{1}$ In principle, Kahane could have considered other safety-related variables in addition to mass in his regression analyses, but he chose not to; if he had, his results would have been different.

He acknowledged elsewhere in his report that in certain types of crashes weight is not the most important vehicle characteristic. Thus, he acknowledged that the static stability factor, or generally speaking the vehicle's center of gravity, plays a large role in the propensity of a vehicle to rollover and cause serious injury or death to its occupants in non-collision events. And he found that the fatality rate of cars struck by light trucks increased as the height and stiffness of the truck front increased, independent of the weight of the striking vehicle. The height and stiffness of light trucks increased the fatality rates of car drivers struck in the left side by $77 \%$ for striking pickups, $135 \%$ for striking SUVs, and 30\% for striking minivans, compared with if the

\footnotetext{
${ }^{1}$ Weight is more readily available than other vehicle characteristics, such as center of gravity, bumper height, door sill height, and frontal stiffness. Even so, weight is not readily available for light trucks, and can vary by how many occupants or how much cargo are in the vehicle.
} 
striking vehicle were a car of the same weight (Table 5 below). Kahane found that SUVs are more aggressive than pickups (Table 5), and four wheel drive trucks more aggressive than two wheel drive trucks (Table 6), independent of the weight of the striking vehicle. Thus Kahane found that fatality rates are strongly influenced not only by crash type but by vehicle type as well, independent of vehicle mass.

Table 5: Relative driver fatality rate in struck car, by striking vehicle type (Source: Kahane 2003, Table 5, page xix)

\begin{tabular}{|l|cccc|}
\hline & \multicolumn{4}{|c|}{ Striking vehicle type } \\
Crash configuration & Car & Pickup & SUV & Minivan \\
\hline Car struck in left side & 100 & $177^{*}$ & $235^{*}$ & $130^{*}$ \\
Car struck in front & 100 & 114 & $132^{*}$ & 104 \\
\hline
\end{tabular}

* Significantly greater than 100 , at the $5 \%$ level

Table 6. Relative driver fatality rate in struck car, by striking vehicle type (Source: Kahane 2003, Table 6-4, page 262)

\begin{tabular}{|l|ccccc|}
\hline & \multicolumn{5}{|c|}{ Striking vehicle type } \\
Crash configuration & Car & 2WD Pickup & 4WD Pickup & 2WD SUV & 4WD SUV \\
\hline Car struck in left side & 100 & $164^{*}$ & $226^{*}$ & $198^{*}$ & $272^{*}$ \\
Car struck in front & 100 & 104 & $145^{*}$ & 109 & $152^{*}$ \\
\hline
\end{tabular}

* Significantly greater than 100 , at the $5 \%$ level

Kahane argued that because vehicle height, stiffness, and center of gravity tend to be somewhat correlated with weight (i.e. light trucks tend to be heavier, higher and stiffer than cars), weight could be used as a proxy for these other vehicle attributes when conducting his regression analyses.

In his latest study, Kahane also acknowledged that any past correlation between vehicle weight and height or size would not necessarily hold in future vehicles, particularly if new materials were used that would reduce vehicle weight while maintaining vehicle size. But although he acknowledges these problems his regression analyses, his important results, do not reflect these reservations.

\section{The Van Auken and Zellner analyses}

In response to the Kahane studies, researchers at the Dynamic Research Institute (DRI) conducted several studies to test the assumption that vehicle weight could be used as a proxy for other vehicle attributes (vehicle size or height) (Van Auken and Zellner, 2002; Van Auken et al., 2003; Van Auken and Zellner, 2005a; Van Auken and Zellner, 2005b). DRI replicated both of Kahane's studies, using similar data and techniques, but included two size variables in addition to weight in their regression analyses. The size variables were trackwidth (the width of the vehicle between the two tires) and wheelbase (the length of the vehicle between the two axles). These size variables do not accurately capture the protective nature of size, but were thought to be better indicators of crush distance than weight. Table 7 summarizes the results of the latest DRI study. DRI found that, holding trackwidth and wheelbase constant, a 100-lb reduction in average car weight would result in a net decrease in the number of fatalities. On the other hand, 
reducing trackwidth or wheelbase would increase fatalities. Combining weight and size reductions would result in a small, but not statistically significant, increase in fatalities.

Table 7. Estimated effect of weight and size reductions on 1999 fatalities, for cars and light trucks (Source: Van Auken and Zellner, 2005b, Tables 2 and 3, page 27, and Tables 5 and 6, page 36)

\begin{tabular}{|l|c|c|c|}
\hline \multirow{2}{*}{ Vehicle parameter change } & \multicolumn{3}{|c|}{ Estmated net change in 1999 US fatalities } \\
involving \\
\cline { 2 - 4 } & Cars & Trucks & Total \\
\hline 100-lb reduction in curb weight & $-836^{*}$ & $-682^{*}$ & $-1,518^{*}$ \\
Corresponding reduction in wheelbase $^{1}$ & $1032^{*}$ & 43 & $1,075^{*}$ \\
Corresponding reduction in trackwidth & $416^{*}$ & $514^{*}$ & $930^{*}$ \\
\hline Combined weight and size reductions & $612^{*}$ & -125 & 487 \\
\hline
\end{tabular}

${ }^{1} 1.01$ inches for cars, 1.21 inches for trucks

${ }^{2} 0.34$ inches for cars, 0.57 inches for trucks

* signficant at the $5 \%$ level

In addition to separating the effects of reductions in weight and size, DRI estimated the separate effect of weight and size reductions on crashworthiness/compatibility and crash avoidance. Table 8 shows that, for cars, the weight and size reductions have about an equal effect on crashworthiness/compatibility and crash avoidance. On the other hand, weight and size reductions have a much greater effect on the crash avoidance of trucks than on their crashworthiness/compatibility.

Table 8. Estimated effect of weight and size reductions on 1999 fatalities, for cars and light trucks, by source of effect (Source: Van Auken and Zellner, 2005b, Tables 2 and 3, page 27, and Tables 5 and 6 , page 36 )

\begin{tabular}{|l|c|c|c|c|}
\hline \multirow{2}{*}{} & \multicolumn{2}{|c|}{ Estmated net change in 1999 US fatalities involving } \\
\cline { 2 - 5 } & \multicolumn{2}{|c|}{ Cars } & \multicolumn{2}{c|}{ Trucks } \\
\cline { 2 - 5 } Vehicle parameter change & $\begin{array}{c}\text { Crash- } \\
\text { worthiness }\end{array}$ & $\begin{array}{c}\text { Crash } \\
\text { avoidance }\end{array}$ & $\begin{array}{c}\text { Crash- } \\
\text { worthiness }\end{array}$ & $\begin{array}{c}\text { Crash } \\
\text { avoidance }\end{array}$ \\
\hline 100 -lb reduction in curb weight & $-472^{*}$ & $-364^{*}$ & -155 & $-528^{*}$ \\
Corresponding reduction in wheelbase & $514^{*}$ & $517^{*}$ & 41 & 2 \\
Corresponding reduction in trackwidth $^{2}$ & $165^{*}$ & $252^{*}$ & 88 & $426^{*}$ \\
\hline Combined weight and size reductions & 208 & $404^{*}$ & -25 & -100 \\
\hline
\end{tabular}

${ }^{1} 1.01$ inches for cars, 1.21 inches for trucks

${ }^{2} 0.34$ inches for cars, 0.57 inches for trucks

* signficant at the $5 \%$ level

The following comes from Kahane's response to the DRI analysis, submitted to the NHTSA docket (Kahane 2005):

The [NHTSA] study only shows the historical relationship between mass - taking into account all the other size attributes that have typically varied with mass - and fatality risk, for vehicles of the same type. If historical relationships between mass and other size attributes continue, in the absence of compelling reasons that would change those relationships [such as a dramatic change in CAFÉ standards], future changes in mass 
are likely to be associated with similar changes in fatality risk. (However, the increased use of advanced restraint systems and sophisticated crash avoidance safety devices [and lightweight but strong composite materials] in recent and future production vehicles could have a noticeable impact on the historical relationship between vehicle mass and fatality risk in future vehicle fleets.)

In that sense, it is irrelevant whether mass, wheelbase, trackwidth or some other attribute is the principal causal factor on fatality risk. If you decrease mass, you will also tend to get less wheelbase, trackwidth and other size attributes. It is only relevant if you can demonstrate that one (or more) of these size attributes other than [or including] mass is the "magic bullet" that explains all the change in fatality risk. In that case, you would have a compelling reason to hold that size attribute constant (or even increase it) while decreasing mass, and the historical relationship between mass and safety would no longer apply. [text added by authors]

The above reiterates two important conclusions of the regression analyses by Kahane and Van Auken and Zellner: that size may be as important, if not more important, than mass in protecting drivers in many types of crashes; and that the analysis of size and mass using historical data is made difficult by their tendency to be correlated, at least in vehicles of current design. All of these statistical studies using actual on-road data are based on the historical relationship between vehicle mass, size, and other vehicle characteristics, and their effect on safety. In effect, they argue that if one takes $100 \mathrm{lbs}$. out of the average compact car it will become an average subcompact car, not only with respect to all the other physical attributes of a subcompact car (safety features, or lack thereof, number of seats, engine size, wheelbase, etc.) but also with respect to the unobserved attributes of the subcompact car drivers' behavior and its environment. None of these studies account for, say, extensive use of lightweight materials, which would decouple the historical correlation between vehicle mass and other characteristics. Evans recently acknowledged this in his most recent article: "Increasing the amount of light-weight materials in a vehicle can lead to lighter, larger vehicles possessing all of the following concurrent characteristics: reduced risk to its occupants in two-vehicle crashes; reduced risk to occupants in other vehicles into which it crashes; [and] reduced risk to its occupants in single vehicle crashes. (Evans, 2004)" 


\section{On-road risks by vehicle type and model}

\section{A. The Wenzel and Ross analyses}

Building on results by others (Hollowell and Gabler, 1996; Gabler and Hollowell, 1998; Joksch, 1998; Joksch et al., 1998; IIHS, 2000), Wenzel and Ross analyzed driver risk by vehicle type and model. "Risk" is the number of driver deaths per year of the selected vehicle, divided by the millions of these vehicles on the road. Typically, the model years of the vehicle being considered and the type of crash may be specified. Because these risks are calculated using data on actual crash fatalities, they account for both the crash avoidance and crashworthiness of vehicle types and models, and include the effects of how differences in vehicle design, driver behavior, and driving environment affect safety. As such, our use of the word "risk" can be taken to mean "risk as driven."

Risk is calculated not only for the drivers of particular vehicles (referred to as "risk-to-drivers"), but also the risk they impose on drivers of other vehicles (referred to as "risk-to-drivers-of-othervehicles", or "risk-to-others"). Usually analysts only present and discuss the risk to occupants of the vehicle in question, as if we as individuals or the society at large don't care about the mayhem caused by aggressive vehicles. The regression analyses in the Kahane and DRI analyses essentially involve the same fatality risks at the model year/make/model level as explicitly reported in Wenzel and Ross.

Figures 8 and 9 show the two types of risk, by vehicle type, in two different formats. Figure 8 plots each type of risk on its own axis. Both risks for minivans are 40 fatalities per million registered-vehicle-years; however, for 1-ton pickups, the risk to their own drivers is 100 fatalities per million registered-vehicle-years, while the risk they impose on drivers of other vehicles is 200 fatalities per million registered vehicle-years. Figure 10 stacks the risks-to-others on top of the risks-to-drivers. The figures show that pickup risk-to-others increases substantially with increasing mass and size, with the risk-to-others of the largest pickups an order of magnitude greater than that of the most popular car model. Note that SUVs (71) and, to a lesser extent, pickups (100 to 123 , depending on size) have risk-to-drivers comparable to those of large cars (75); Figure 10 indicates that the additional risk to SUV drivers in rollover crashes (34, compared to 14 in large cars) overcomes their reduced risk in crashes with another vehicle (37, compared to 61 in large cars). Because of the relatively small numbers of fatalities in each vehicle type, differences in risk of less than $10 \%$ between vehicle types are not statistically significant. 
Figure 8. Risk-to-drivers, and risk-to-drivers-of-other-vehicles, by vehicle type; differences between vehicle types less than $10 \%$ are not statistically significant

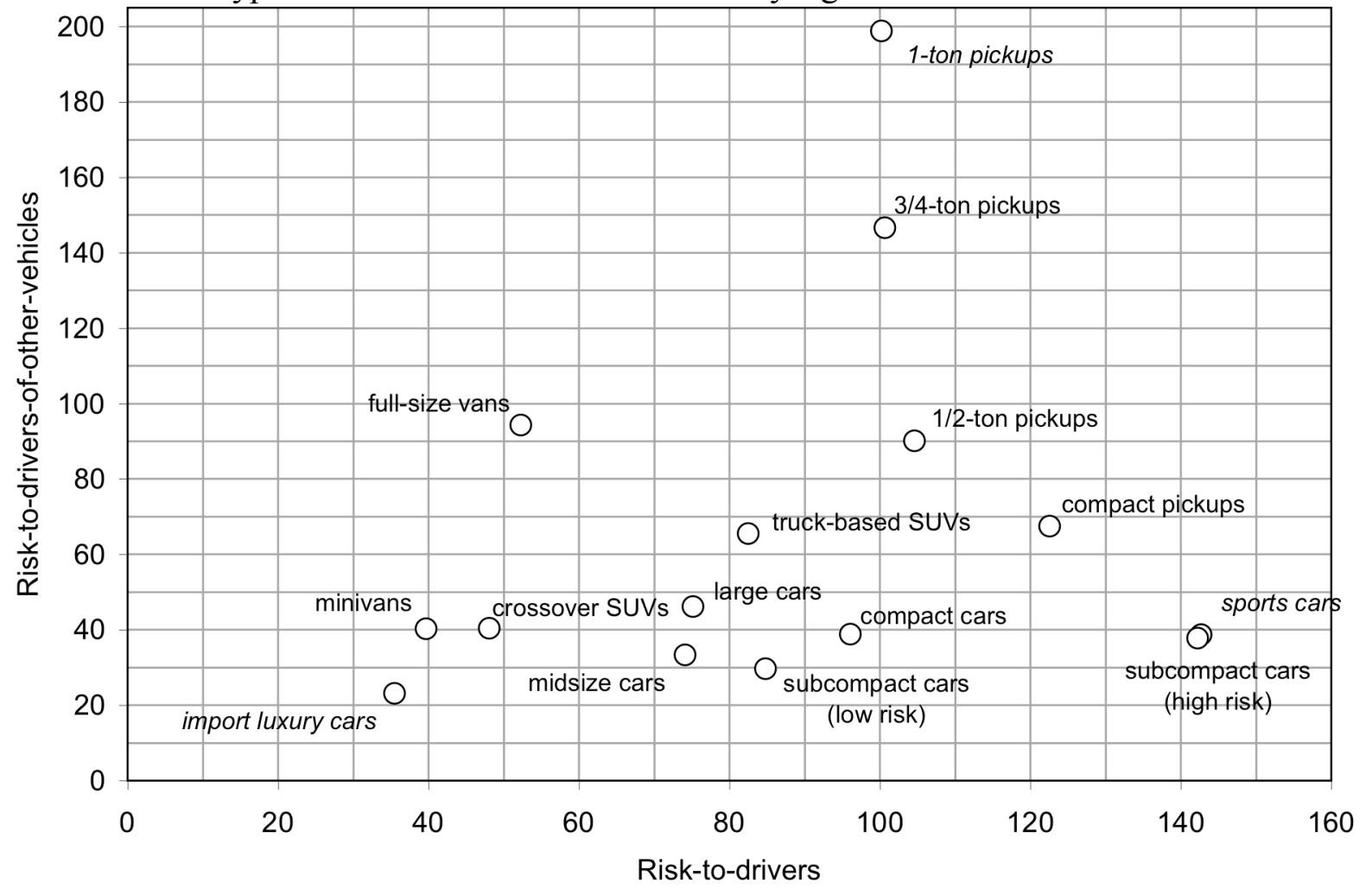

Figure 9. Risk-to-drivers, and risk-to-drivers-of-other-vehicles, by vehicle type; differences between vehicle types less than $10 \%$ are not statistically significant

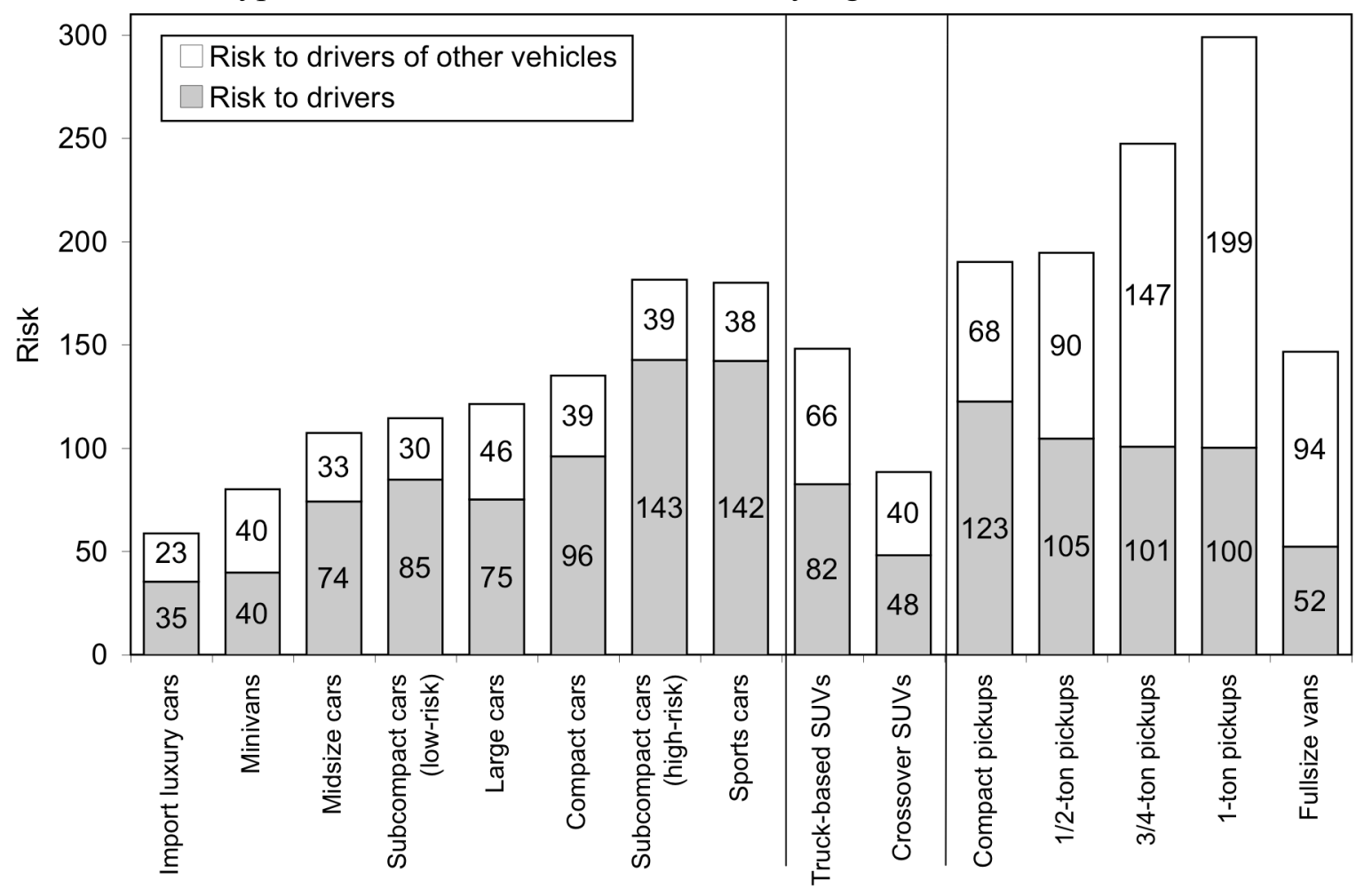


Figure 10. Risk-to-drivers in rollover crashes and all other crashes, by vehicle type; differences between vehicle types less than $10 \%$ are not statistically significant

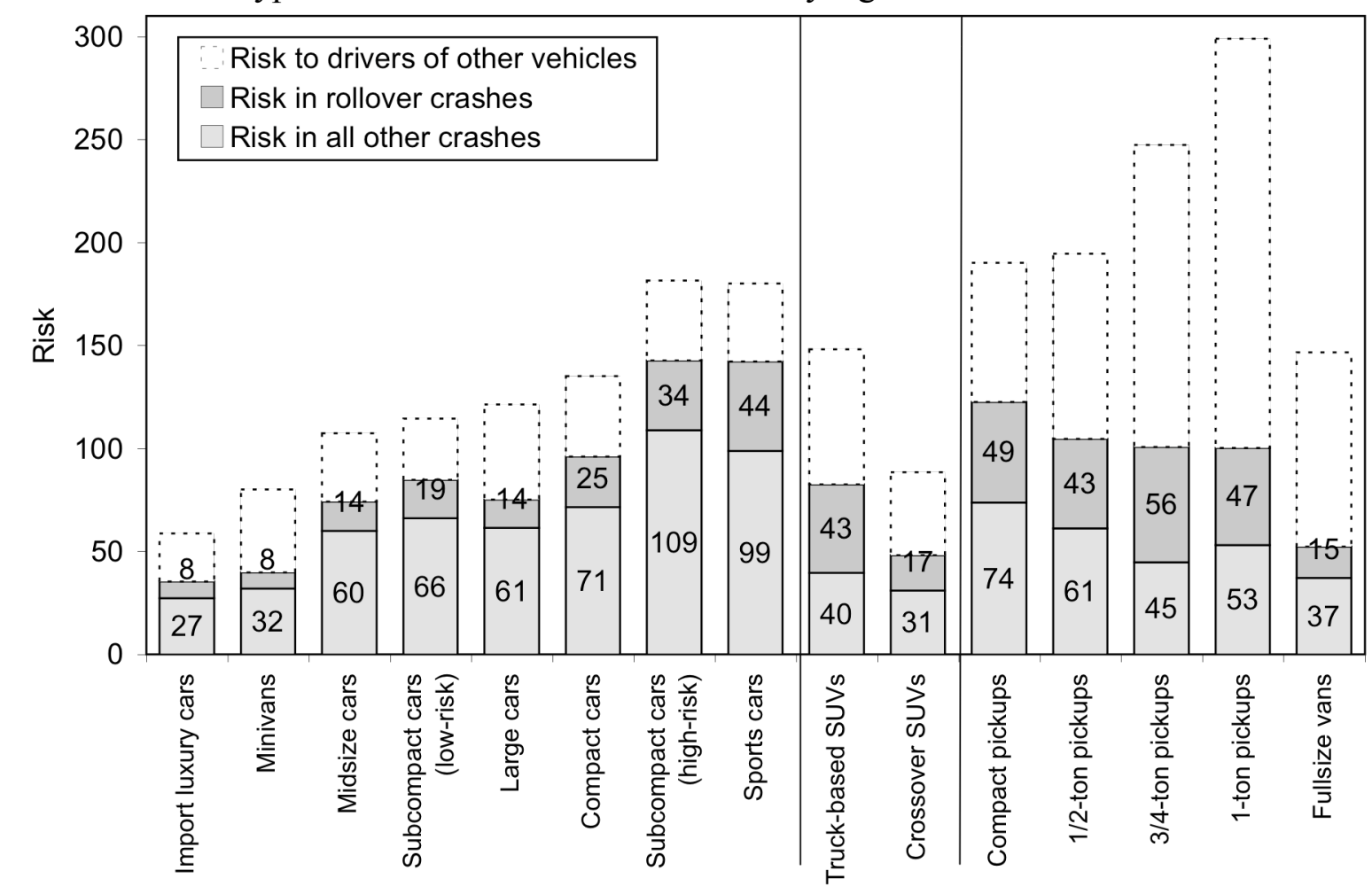

Figure 11 plots risk against risk-to-others in a scatterplot similar to Figure 8, but shows the risks for the most popular vehicle models. Because of the relatively small numbers of fatalities in each model, differences in risk of less than $20 \%$ between models are not statistically significant. The analysis of risks by vehicle make/model allows the study of whether who drives these vehicles, as well as how and where they are driven, affects their risks. Note that there can be a wide range in risk, even for models in the same class. For instance, five subcompact models (Neon, Cavalier, Sunfire, Escort, and Accent) have much higher risk-to-drivers than all other subcompact models; we put these subcompact cars into a separate "high-risk subcompacts" category in Figures 8 through 10. Similarly, there is a wide range in both types of risk for SUV models, with the crossover models RX300 and CR-V having much lower risks than some truckbased SUV models. (Because they have such high risk-to-drivers-of-other-vehicles, 3/4-ton and 1-ton pickup models are not shown in Figure 11.) 
Figure 11. Risk-to-drivers in rollover crashes and all other crashes, by vehicle type; differences between models less than $20 \%$ are not statistically significant

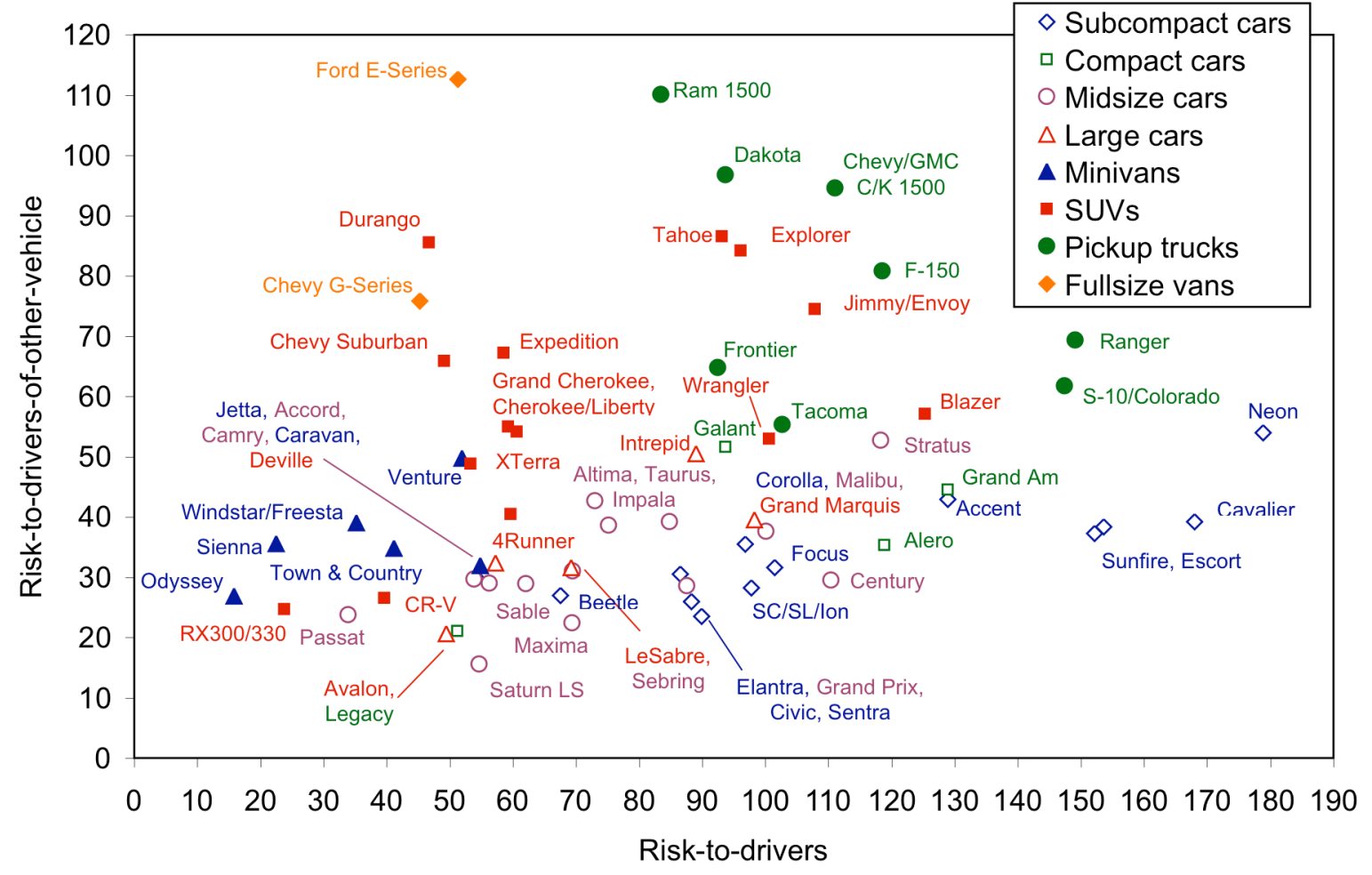

Two aspects of historical SUV design account for their high rollover risk and risk-to-others. SUVs which were based on pickup truck chassis tend to have high centers of gravity, and very stiff, and high, longitudinal frame rails (Figure 12) that often override car bumpers and door sills, and intrude into the passenger compartment of the car. The newer crossover SUV designs, which tend to have lower centers of gravity than truck-based SUVs and unibody construction similar to cars, tend to have lower risk both to their own drivers and to drivers of other vehicles, as shown by the open symbols in Figure 13. These newer crossover SUV designs not only have better safety records than truck-based SUVs; they provide roughly 3 to 4 miles per gallon higher fuel economy for a given interior volume (Figure 14). 
Figure 12. Stiff frame rails of pickups and truck-based SUVs (model year 2002 Dodge Ram 150 pickup truck)

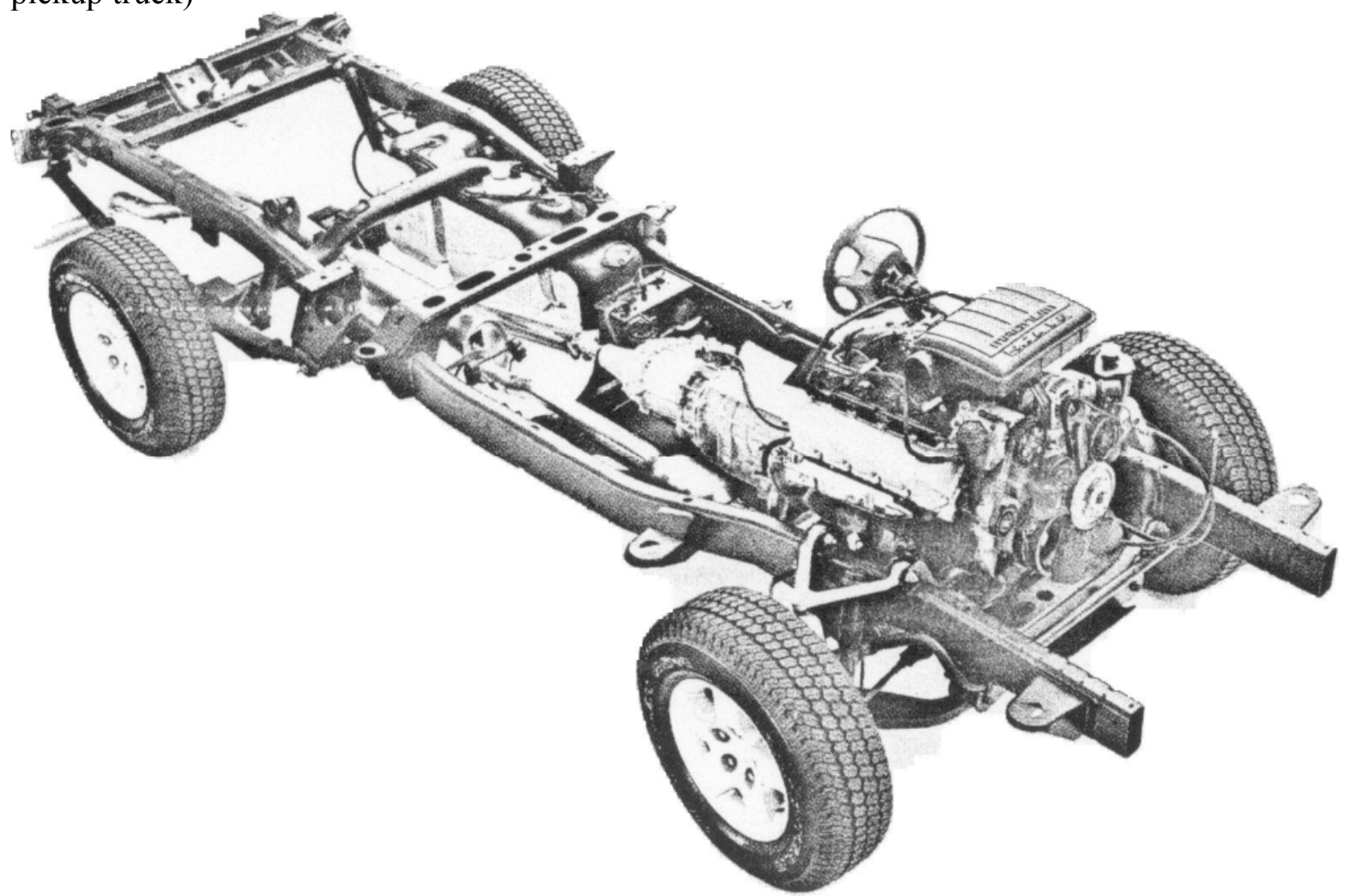

Figure 13. SUV risk-to-drivers and risk-to-drivers-of-other-vehicles, by SUV type and model

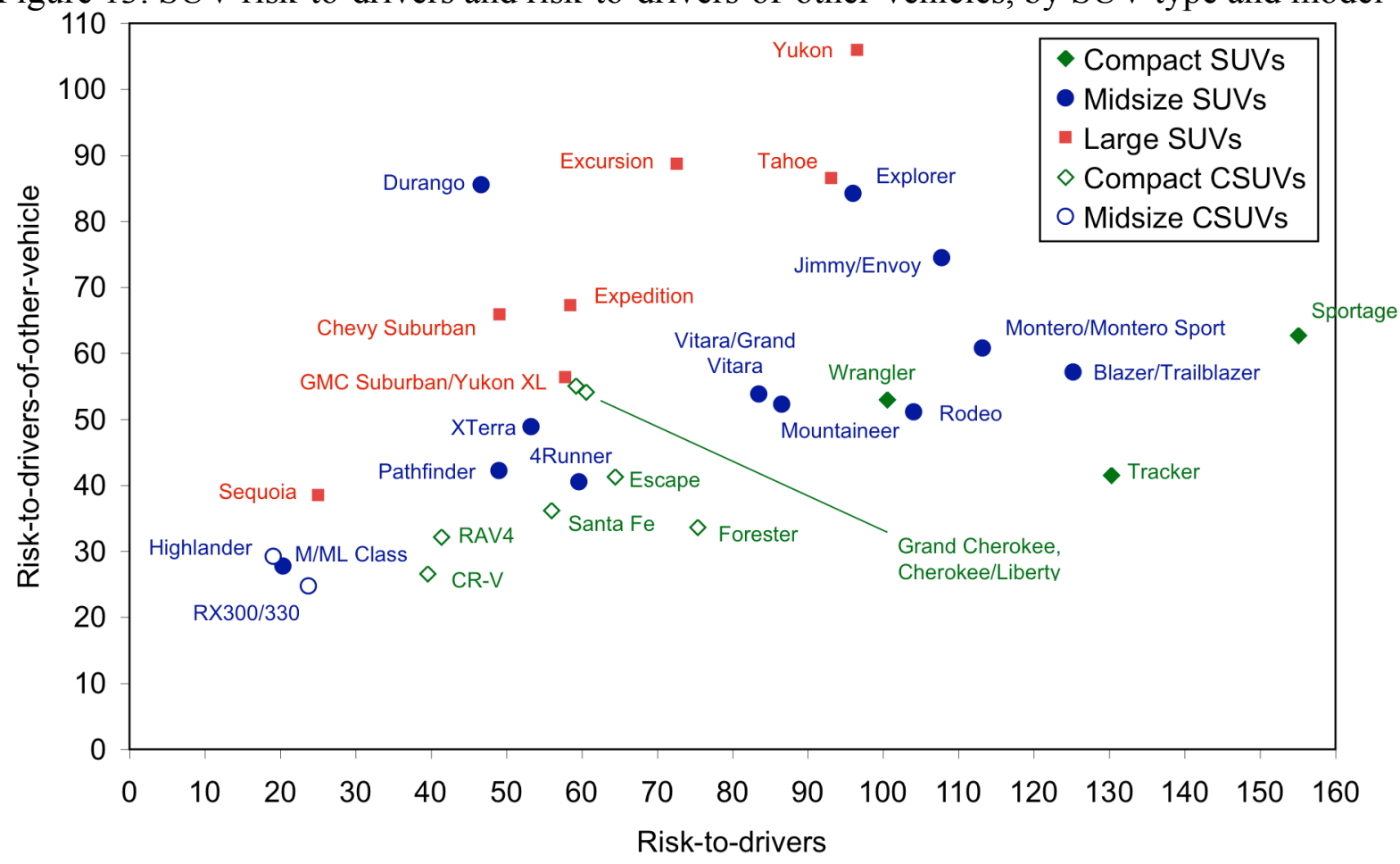


Figure 14. Fuel economy and interior volume of 2005 truck-based and crossover SUV models (4WD versions)

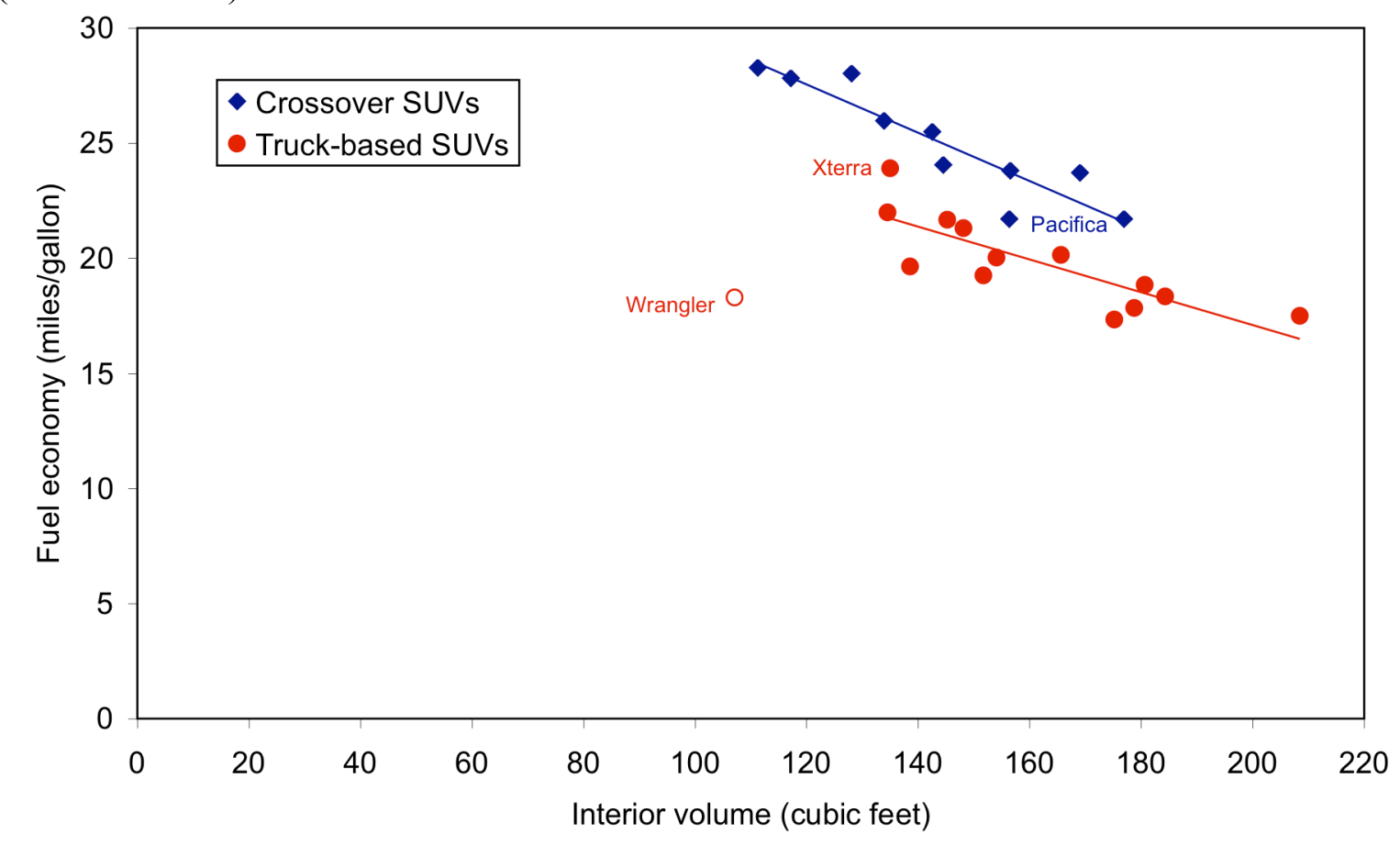

B. The effect of drivers and environment on risk

Recall that, because these risks are calculated using data on actual crash fatalities, they include the effects of how differences in vehicle design, driver behavior, and driving environment affect safety by vehicle type and model. We try to account for these driver and environment characteristics. For instance, using California registration data, we analyzed risk in urban and rural counties of the state; Figure 15 indicates that each type of risk is greater in rural areas than urban areas, for all vehicle types. Therefore, because pickups tend to be driven more in rural areas, our estimate of pickup risk both to own drivers and other drivers is overstated due to greater use in rural areas, where fatality risks are greater. 
Figure 15. Risk to drivers and to others, by vehicle type and area, California 1995-02

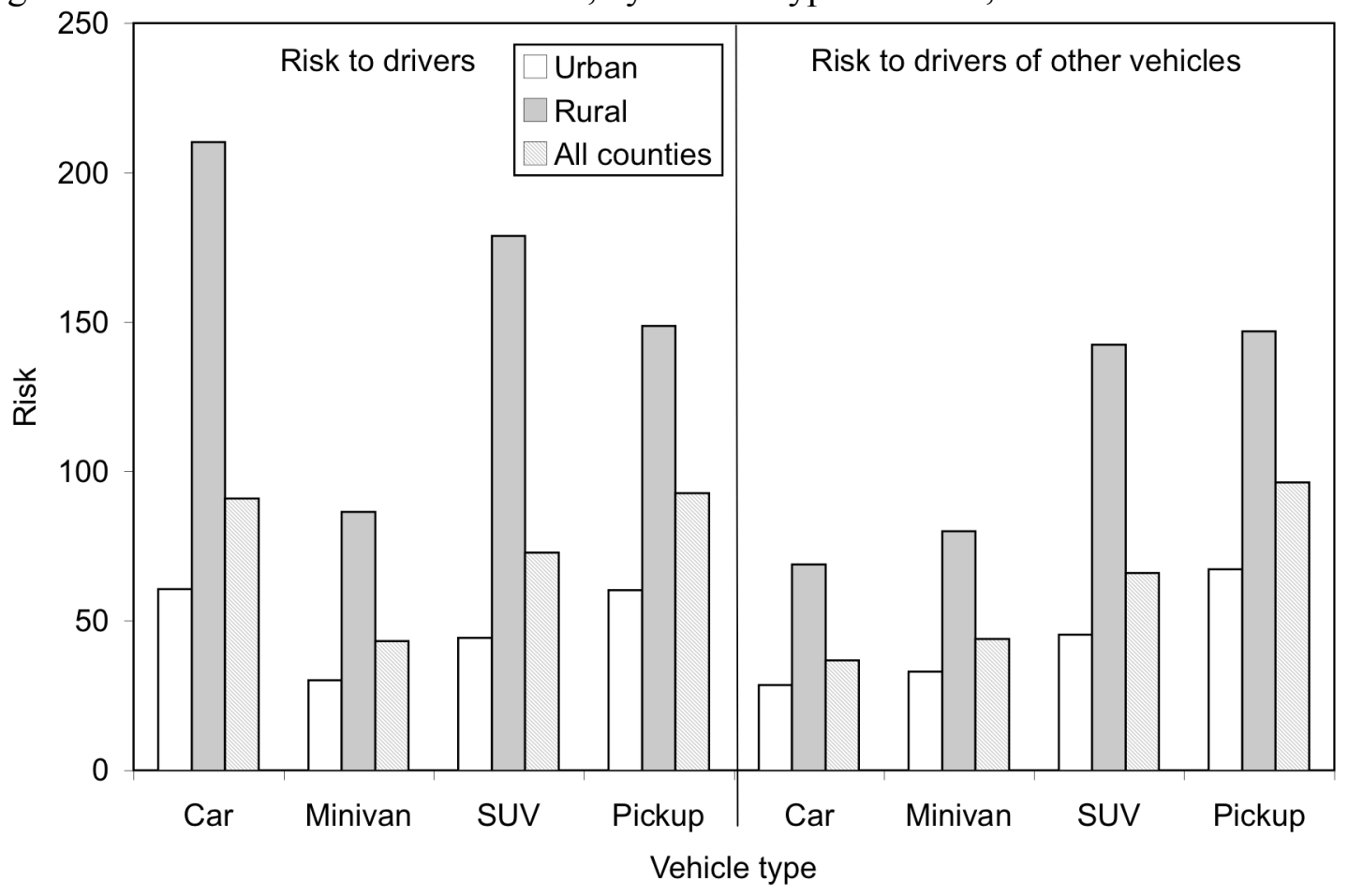

Similarly, large differences in driver characteristics can make inflate the risks of particular vehicle types or models. We used a measure of illegal driving developed by Kahane to compare driver characteristics across vehicle types and models. This "bad driver rating" is based on alcohol or drug involvement, driving without a valid license or reckless driving in the current crash, as well as the driver's driving record in the last three years. Figure 16 compares the bad driver rating by vehicle type with risk-to-drivers and population density. The population density where the fatality occurred is expressed by the relative diameter of the bubble for each vehicle type; smaller bubbles had a larger percentage of fatal crashes in rural areas. The figure suggests that risk to drivers increases with increasing bad driver rating and decreasing population density. However, there are important exceptions to these trends. Import luxury cars, which have the lowest risk to driver, have some of the worst drivers, on average. On the other hand, sports cars have extremely high risks, yet are mostly driven in relatively safe urban environments. And the high-risk subcompact cars have nearly twice the risk of the low-risk subcompact cars, but about the same bad driver rating and degree of rural driving. 
Figure 16. Effect of bad driver rating and population density on risk-to-drivers, by vehicle type

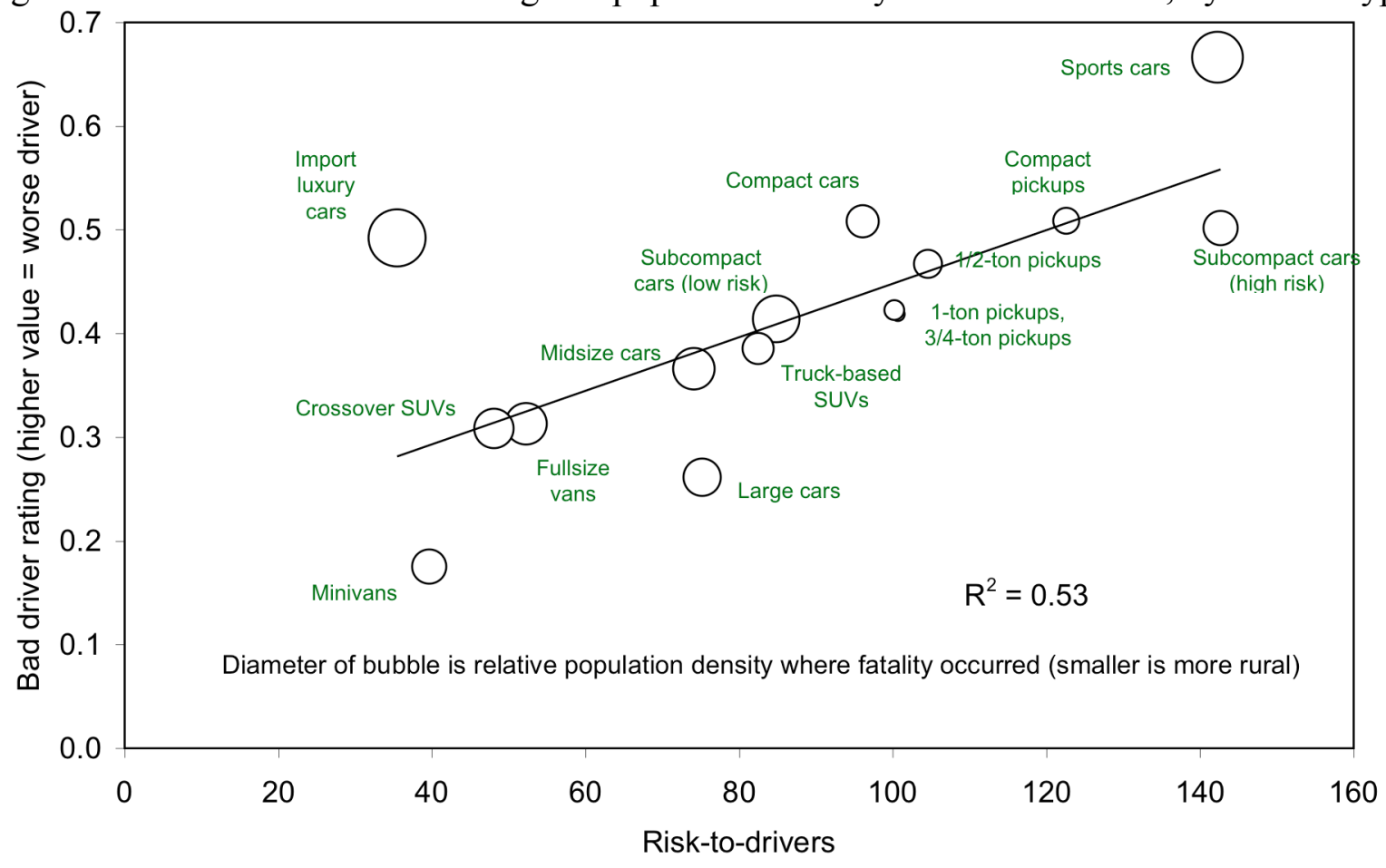

The Wenzel and Ross analysis by vehicle make and model points out a limitation in Kahane's analysis. In simple terms, Kahane's approach essentially models what would happen if the historical risk of model year 1991-99 cars were replaced with the historical risk of 1991-99 models that were 100 pounds lighter. In other words, he argues that if one takes $100 \mathrm{lbs}$. out of a compact car it will become a subcompact car, not only with respect to all the other physical attributes of a subcompact car (safety features, or lack thereof, number of seats, engine size, wheelbase, etc.) but also with respect to the unobserved attributes of the subcompact car drivers' behavior and its environment. However, as Figure 17 indicates, there can be a large range in risk-to-drivers, even for car models with similar mass. The figure indicates that there is not a strong relationship between the overall fatality risk and the weight of individual car models. The risks in Figure 17 do not account for differences in where or how car models may be driven; however, our analyses indicate that these differences are not large enough or consistent enough to explain the large variation in risk for models of the same weight. Some factors other than weight appear to better predict the fatality risk of a car model; for instance, car models with Ford, GM, or Daimler-Chrysler nameplates consistently have higher risk than models with Japanese or German nameplates; and resale value after five years is much more strongly correlated with fatality risk (Wenzel and Ross, 2005). 
Figure 17. Risk-to-drivers and vehicle weight, for individual car models

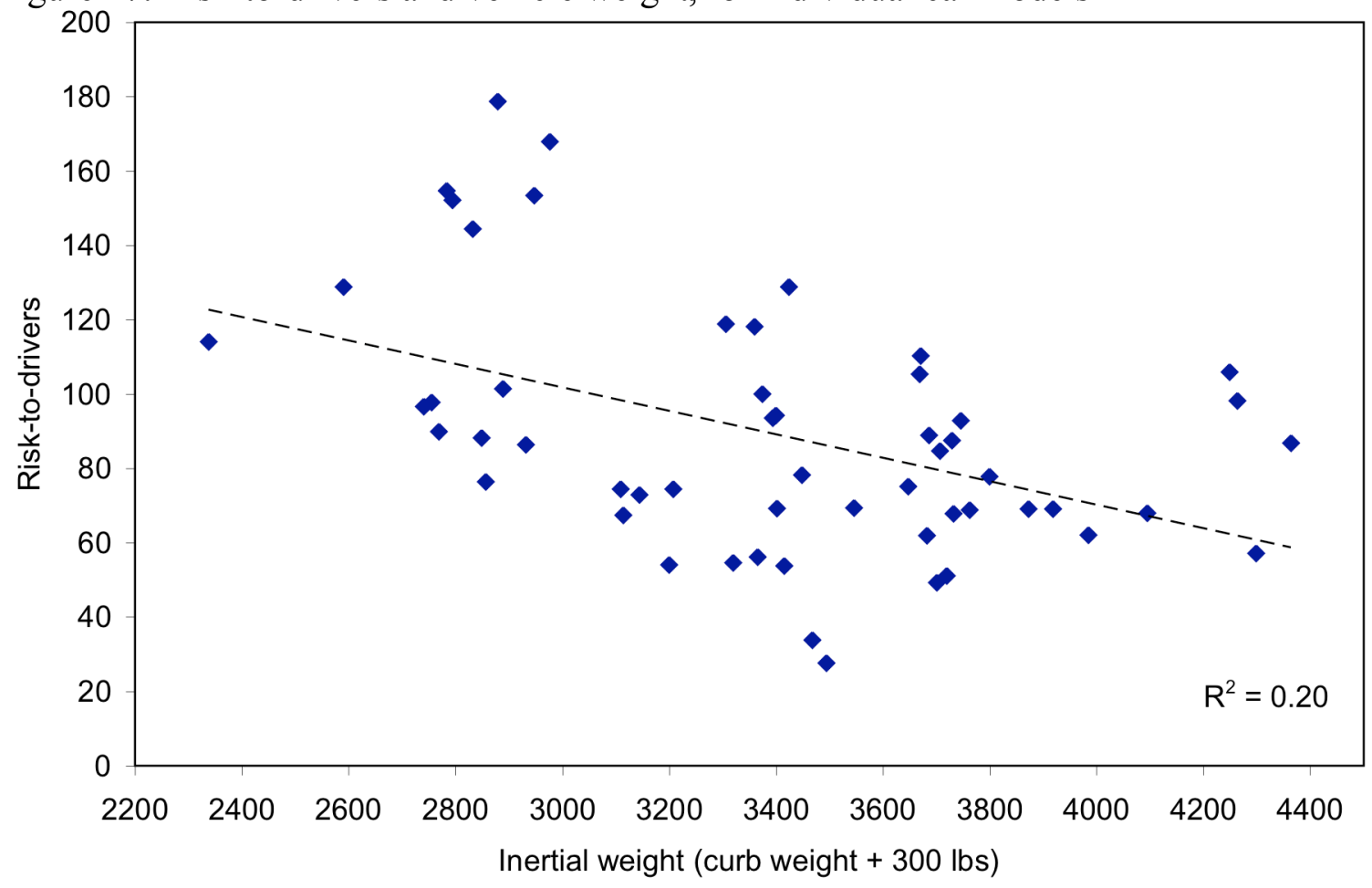

Another limitation of all these statistical analyses (Kahane, Van Auken/Zellner, Wenzel/Ross) is that they do not, and cannot, account for all differences in driver characteristics and behavior, and environmental conditions, that likely greatly influence whether a vehicle is involved in a fatal crash. Kahane and Van Auken/Zellner made great attempts to account for the most obvious of these variables: driver age and gender, alcohol and drug involvement, and driving record. However, other important variables, such as income and education, are not available in the FARS or NASS data (although may be available in insurance claim data). Other more subtle differences between drivers, such as driving skill and experience, also are not available, and are difficult to measure.

C. Steps to improve the compatibility of cars and light trucks

Light truck manufacturers recently agreed to adopt voluntary measures to address the aggressivity of light trucks. These measures consist of, 1) for frontal compatibility, lowering the bumpers or lowering the chassis of light trucks and 2) for side impact compatibility, installing curtain side airbags in cars. A recent IIHS study suggests that SUV models which comply with these measures have substantially reduced risk-to-others compared with non-complying models; but complying pickups do not show improved compatibility. LBNL analysis suggests that crossover SUVs, which generally comply with the compatibility measures, have substantially reduced risk, while truck-based SUVs have not, whether or not they comply with the compatibility measures. However, the LBNL analysis suggests that all pickups, of all sizes (compact to 1-ton), and not just complying models, have reduced risk-to-others. It appears that there are not yet sufficient data to assess whether the compliant truck-based SUVs and pickups are less aggressive than their non-compliant counterparts. 


\section{New research on injury causation}

Detailed research on injury causation by medical doctors teaming with engineers opens a new way to address the mass/safety issue. And, incidentally, it provides an independent approach to the issue of mass reduction and safety. There are three main proximate causes of injury to occupants in a crash, 1) "contact", either striking intruding surfaces or striking hard surfaces in an undeformed passenger compartment, 2) "restrained acceleration", in which occupant experiences injurious deceleration by the safety constraints (seat belts, airbags, head rests), and 3 ) a sequence of such events, especially including occupant ejection, as may particularly occur in rollovers.

Contact injuries dominate for belted occupants in the most modern vehicles (see, for example, Figures 3 and 4 in Ross et al., 2006). Contact injuries tend to be localized in the vehicle and to occur rapidly. They are not sensitive to the the mass of the vehicle as a whole. Critical vehicle characteristics for safety in "contact" situations are vehicle stability, use and quality of the restraints, energy absorbing space outside the occupant compartment, and a strong occupant compartment itself.

The "restrained acceleration" and "sequential" injuries tend to involve most of the vehicle and evolve over a longer period. Some analysts, especially Evans, have argued that vehicle mass must be important to injury because the overall deceleration of the lighter vehicle and its occupants during a two-vehicle crash is proportional to the ratio of the heavier to the lighter masses. He is right that restrained acceleration can be risky. A stiff vehicle that is relatively light may, because it is light, be strongly accelerated as a whole, causing injury. However, as one might expect, the evidence is that "restrained acceleration" is much less common as the cause of serious injury or death than contact mechanisms.

Recent research in this area involves a few teams of engineers and medical doctors that collaborate in "on-the-spot" and "in-depth" analysis of crashes near each team's site. Some teams attempt to reach automotive crashes within 10 to 20 minutes so they can better determine vehicle trajectories and interview witnesses. The research appears to be particularly well organized and supported around certain European cities, such as sites within Hanover and Dresden. Supporting the contact perspective, European specialists associated with this research say: "The results from this project have overturned the original views about compatibility, ${ }^{2}$ which thought that mass and the mass ratio were the dominant factors (Edwards et al., 2001)." "Moreover, if mass appears to be the main parameter linked to aggressivity of cars, it is because this is the easiest and universal parameter that is collected in all accident databases (Faerber, 2001)." "The scientific community now agrees that mass does not play a direct role in compatibility (Delannoy and Faure, 2003)." The concept of these scientists is that, for the range of vehicle masses typical in Europe, mass is not fundamental to compatibility. Instead they find intrusion is the proximate cause of most severe injuries, and intrusion is primarily associated with factors like the stiffness and geometry of vehicles, not with mass as such.

\footnotetext{
${ }^{2}$ Compatibility means features in a vehicle that tend to protect occupants of other vehicles in a multi-vehicle crash.
} 
In-depth study of crashes is also underway in the US (the Crash Injury Research and Engineering Network, or CIREN, and the National Accident Sampling System Crashworthiness Data System, or NASS CDS). Results, though limited, again suggest the dominance of contact, especially intrusion (Augenstein et al., 2005; Ross et al., 2006). These studies suggest that up to 10 or $15 \%$ of serious injuries may be associated with restrained acceleration. This preliminary work suggests that only a small fraction of serious injuries are sensitive to vehicle mass. 


\section{Conclusions}

Mass reduction is critical if vehicles are to meet greenhouse gas and oil savings goals. Two aspects of vehicle design are involved: Risks can be reduced by improvement of vehicle structures. Mass can be reduced by making several different design changes.

In crashes with a stationary object, frontal crush space, rather than mass, provides protection to the vehicle occupants, Mass offers protection in head-on car-car, and perhaps truck-truck, crashes when there is a substantial difference in mass between the two vehicles. In head-on crashes between a car and a truck, differences in frontal height and/or stiffness, rather than mass, are the most important factor. Car occupants that are struck in the side by a light truck are at special risk because there is little room for crush space in the side structure of a car. The aggressivity of a striking truck can be mitigated either by lowering the bumper or the stiff parts of the truck, or by making the front of the truck less stiff. More detailed tests are needed to determine which characteristic is more important in defining a truck's aggressivity. Raising the car bumper height (in head-on crashes) or door sill height (in side impact crashes), reinforcing the occupant compartment, and installing side curtain airbags, may increase protection to car occupants struck by a light truck.

Increased mass improves neither the crash avoidance ability or crashworthiness of a vehicle in a rollover crash. Although SUVs and pickups are more likely to roll over than passenger cars which are generally lighter, the height of a vehicle's center of gravity has a substantially greater impact than mass on the propensity of a vehicle to roll over. The center of gravity can be lowered by lowering the overall vehicle height, or by increasing its track width.

In statistical analyses, mass has been shown to have a protective effect in crashes with an object and with another vehicle. However, recent research indicates that mass is merely a proxy for other characteristics that are more important for crashes between cars and trucks, such as frontal height and stiffness. 


\section{References}

Ahmad, S., Greene, D.L., 2004. "The effect of fuel economy on automobile safety: a reexamination." Transportation Research Board paper 05-1336.

An, F., Friedman, D., Ross, M., 2002. "Near-term fuel economy potential for light-duty trucks." SAE Technical Paper Series 2002-01-1900, Warrendale, Pennsylvania.

Arbelaez, R.A., Baker, B.C., Nolan, J.M., 2005. "Delta Vs for IIHS side impact crash tests and their relationship to real-world crash severity." Proceedings of the $19^{\text {th }}$ International Technical Conference on the Enhanced Safety of Vehicles, paper number 05-0049. http://wwwnrd.nhtsa.dot.gov/departments/nrd-01/esv/19th/esv19.htm

Augenstein, J. et al., 2005. "The role of intrusion in injury causation in frontal crashes", Society of Automotive Engineers, Technical Paper 2005-10-1376.

Crandall, R.W., Graham, J.D., 1989. "The effect of fuel economy standards on automobile safety." Journal of Law and Economics 32:97-118.

DeCicco, J., 2005. Steel and iron technologies for automotive lightweighting. Environmental Defense, New York, NY.

DeCicco, J., Ross, M. 1993. An updated assessment of the near-term potential for improving automotive fuel economy. American Council for an Energy-Efficient Economy, Washington DC.

Delannoy, P., Faure, J., 2003. "Compatibility assessment proposal close from real life accident." Proceedings of the $18^{\text {th }}$ International Technical Conference on the Enhanced Safety of Vehicles, paper number 94. http://www-nrd.nhtsa.dot.gov/departments/nrd-01/esv/18th/esv18th.htm

Edwards, M., Happian-Smith, J., Davies, H., Byard, N., Hobbs, A., 2001. "The essential requirements for compatible cars in frontal collisions." Proceedings of the $17^{\text {th }}$ International Technical Conference on the Enhanced Safety of Vehicles, paper number 158. http://wwwnrd.nhtsa.dot.gov/pdf/nrd-01/Esv/esv17/Proceed/search.pdf

Evans, L., 2004a. Traffic Safety. Science Serving Society, Bloomfield Hills, MI.

Evans, L., 2004b. How to make a car lighter and safer. SAE Technical Paper Series, 2004-011172. Society of Automotive Engineers, Warrendale, PA.

Faerber, E., 2001. "EEVC research in the field of improvement of crash compatibility between passenger cars." Proceedings of the $17^{\text {th }}$ International Technical Conference on the Enhanced Safety of Vehicles, paper number 444 . http://www-nrd.nhtsa.dot.gov/pdf/nrd01/Esv/esv17/Proceed/search.pdf

Gabler, H.C., Hollowell, W.T., 1998. The aggressivity of light trucks and vans in traffic crashes. SAE Technical Paper Series 980908, Warrendale, Pennsylvania. 
GAO, 2005. Vehicle Safety: Opportunities Exist to Enhance NHTSA's New Car Assessment Program. U.S. Government Accountability Office, Washington, DC.

Heavenrich, R., 2005. Light-Duty Automotive Technology and Fuel Economy Trends: 1975 Through 2005. EPA 420-S-05-0001. U.S. Environmental Protection Agency, Washington, D.C.

Hollowell, W.T., Gabler, H.C., 1996. NHTSA's vehicle aggressivity and compatibility research program. In: Proceedings of the Fifteenth International Technical Conference on the Enhanced Safety of Vehicles, Volume 1, pp. 576-592. Paper no. 96-S4-0-01.

Horne, J.A., Raynor, L.A., 1995. Falling Asleep at the Wheel. Transportation Research Lab, UK, report 168 .

Insurance Institute for Highway Safety (IIHS), 2000. Status report special issue: driver death rates. Vol. 35 , no. 7.

Joksch, H., Massie, D., Pichler, R., 1998. Vehicle aggressivity: fleet characterization using traffic collision data. DOT HC 808 679. University of Michigan Transportation Research Institute, Ann Arbor, Michigan.

Joksch, H., 1998. Fatality risks in collisions between cars and light trucks. DOT HS 808802. University of Michigan Transportation Research Institute, Ann Arbor, Michigan.

Kahane, C.J., 1997. Relationships between vehicle size and fatality risk in model year 1985-93 passenger cars and light trucks. NHTSA DOT HS 808570. U.S. Department of Transportation, National Highway Traffic Safety Administration, Washington, D.C.

Kahane, C.J., 2003. Vehicle weight, fatality risk and crash compatibility of model year 1991-99 passenger cars and light trucks. NHTSA DOT HS 809 662. U.S. Department of Transportation, National Highway Traffic Safety Administration, Washington, D.C.

Kahane, C.J., 2004. Response to docket comments on NHTSA technical report "Vehicle weight, fatality risk and crash compatibility of model year 1991-99 passenger cars and light trucks". Submission to docket no. NHTSA-2003-16318. U.S. Department of Transportation, National Highway Traffic Safety Administration, Washington, D.C.

Khazzoom, D.J., 1994. "Fuel efficiency and automobile safety: single-vehicle highway fatalities for passenger cars." Energy Journal 15(4): 49-101.

Lovins, A.B., Data, E.K., Bustnes, O.E., Koomey, J.G., Glasgow, N.J., 2005. Winning the Oil Endgame. Rocky Mountain Institute, Snowmass, CO, 1st edition, pp 57-61, available at http://www.oilendgame.com/ReadTheBook.html

Massie, D.L., Campbell, K.L., Williams, A.F., 1995. "Traffic accident involvement rates by driver age and gender." Accident Analysis and Prevention 27: 73-87. 
McCartt, A.T., et al., 2005. Cell phones and driving: a review of research. Insurance Institute for Highway Safety: Arlington VA.

McEvoy, S.P., Stevenson, M.R., McCartt, A.T., Woodward, M., Haworth, C., Palamara, P., Cercarelli, R., 2005. "Role of mobile phones in motor vehicle crashes resulting in hospital attendance: a case-crossover study." British Medical Journal, bmj.38537.397512.55 (published July 12, 2005).

Newstead, S.V., Farmer, C.M., Narayan, S., Cameron, M.H., 2003. "U.S. consumer crash test results and injury risk in police-reported crashes", Traffic Injury Prevention 4, 113-127.

NHTSA, 2006. The 100-Car Naturalistic Driving Study Phase II. NHTSA DOT HS810593. U.S. Department of Transportation, Washington, DC.

http://www-nrd.nhtsa.dot.gov/departments/nrd-13/driver-distraction/pdf/100CarMain.pdf

Noland, R.B., 2004. “Motor vehicle fuel efficiency and traffic fatalities.” Energy Journal 25(4): $1-22$.

Ross, M., Patel, D., Wenzel, T., 2006. "Vehicle Design and the Physics of Traffic Safety." Physics Today vol. 59, issue 1, page 49-54.

Shahed, S.M., 2006. An analysis of assisted turbocharging with light hybrid powertrain. SAE Technical Paper Series, 2006-01-0019. Society of Automotive Engineers, Warrendale, PA.

Van Auken, R.M., Zellner, J.W., 2002. An assessment of the effects of vehicle weight on fatality risk in model year 1985-98 passenger cars and 1985-97 light trucks. DRI-TR02-02. Dynamic Research, Inc., Torrance, California.

Van Auken, R.M., Zellner, J.W., Boughton, J.P., Brubacher, J.M., 2003. A further assessment of the effects of vehicle weight and size parameters on fatality risk in model year 1985-98 passenger cars and 1985-97 light trucks. DRI-TR03-01. Dynamic Research, Inc., Torrance, California

Van Auken, R.M., Zellner, J.W., 2005a. An assessment of the effects of vehicle weight and size on fatality risk in 1985 to 1998 model year passenger cars and 1985 to 1997 model year light trucks and vans. SAE Technical Paper Series, 2005-01-1354. Society of Automotive Engineers, Warrendale, PA.

Van Auken, R.M., Zellner, J.W., 2005b. Supplemental results on the independent effects of curb weight, wheelbase, and track on fatality risk in 1985-1998 model year passenger cars and 19861997 model year LTVs. DRI-TR05-01. Dynamic Research, Inc., Torrance, California.

Wenzel, T.P., Ross, M., 2005. "The effects of vehicle model and driver behavior on risk." Accident Analysis and Prevention 37: 479-494. 